\title{
Circulation patterns linked to extreme wet and dry conditions in Mozambique, relationship with climatic modes, and changes since 1961
}

Chibuike Chiedozie Ibebuchi ( $\sim$ chibuike.ibebuchi@uni-wuerzburg.de ) University of Würzburg

\section{Research Article}

Keywords: Mozambique, Circulation types, Africa south of the equator, climatic modes, rainfall

Posted Date: April 26th, 2021

DOI: https://doi.org/10.21203/rs.3.rs-462878/v1

License: (c) (1) This work is licensed under a Creative Commons Attribution 4.0 International License.

Read Full License 
1 Circulation patterns linked to extreme wet and dry conditions in

2 Mozambique, relationship with climatic modes, and changes since

3

4

5

6

7

8

9

10

11

12

13

14

15

16

17

18
1961

Chibuike Chiedozie Ibebuchi
6

(1)

Institute of Geography and Geology, University of Würzburg, Am Hubland, 97074

Würzburg, Germany

Corresponding author's email: chibuike.ibebuchi@uni-wuerzburg.de 
20 Abstract

21 This study investigates circulation types (CTs) in Africa south of the equator that can be associated with extreme wet and dry conditions in Mozambique; the relationship between the

23 CTs and climatic modes in the south Indian Ocean; and changes in the frequency of 24 occurrence of the CTs since 1961. Obliquely rotated principal component analysis applied to 25 sea level pressure field from NCEP-NACR for the 1961-2020 period was used to derive 26 physically interpretable CTs. At the synoptic scale, widespread rainfall in Mozambique was 27 found to be related to widespread cyclonic activity on the Mozambique landmass and in the southwest Indian Ocean, coupled with abundant onshore moisture advection by southeast winds. On average, this circulation type (CT) was found to be significantly related to the

30 positive phase of the Indian Ocean Dipole and the El Niño climatic modes, which both favor

31 anomalous warming of the (western) tropical Indian Ocean. The aforementioned climatic modes equally constrain the annual frequency of occurrence of the CT, possibly due to the anomalous deepening of cyclonic activity in the southwest Indian Ocean during their active

34 periods. Since 1961 the frequency of occurrence and days of persistence of the 35 aforementioned CT has increased, suggesting a possible increase in the vulnerability of the 36 hydroclimate of Mozambique. Extreme dry conditions in Mozambique can be related to 37 widespread anticyclonic activity on the Mozambique landmass and the southwest Indian 38 Ocean, coupled with the weakening of onshore moisture advection.

39 Keywords: Mozambique; Circulation types, Africa south of the equator, climatic modes, 40 rainfall 


\section{Introduction}

Mozambique boarded to the east by the Mozambique Channel, which is a tropical cyclone

45 basin, is prone to natural disasters. Disease outbreak, such as cholera, is likely to be 46 aggravated in the regions that are vulnerable to flood [1]. The lack of local capacity and

47 vulnerability of the country puts it in a precarious economic position. Under greenhouse gasinduced climate change, the intensity of tropical storms is expected to increase hence aggravating the human consequences of disasters in the region [2]. Also, according to [2], dry spells are equally expected to increase in southern Africa under climate change. Preparedness is a basic factor in curtailing the effects of natural disasters. Several works of literature have focused on the predictability of tropical cyclones in the southwest Indian Ocean $[3,4,5,6,7]$.

This study extends the predictability of extreme wet and dry conditions in Mozambique in the light of identifying synoptic situations in Africa south of the equator that can favor extreme rainfall and dry conditions in Mozambique.

Though the El Niño southern oscillation (ENSO) is a major driver of the inter-annual variability of rainfall in southern Africa (with the inclusion of Mozambique) [8]. Other lowfrequency modes of variability such as the Subtropical Indian Ocean dipole (SIOD) [9], the Indian Ocean dipole [10], Madden-Julian Oscillation [11], and the Southern Annular Mode (SAM) [12], play significant roles in rainfall variability in the subcontinent. During the warm phase of ENSO and the negative phase of the SIOD, rainfall decrease can be expected in large parts of southern Africa, mainly due to sea surface temperature (SST) anomalies in the southwest Indian Ocean and adjustments in the regional atmospheric circulation patterns in the sub-continent $[8,9,4,13]$. During the cold phase of ENSO and the positive SIOD, a reverse condition is expected. In the regional context of Africa, the IOD is expected to have a more 
robust influence in East Africa. The climatic modes also influence the climate of tropical cyclones in the southwest Indian Ocean $[14,15]$.

A land-based convergence zone which extends off the southeast coast of southern Africa known as the South Indian Ocean Convergence Zone that form during austral summer (DJF) forms the major relationship between large-scale atmospheric circulation and the austral summer rainfall variability in southern Africa $[8,16]$. Generally, the convergence of moisture transported from the tropical South Atlantic Ocean, driven by the cyclonic circulation at the Angola low; the southwest Indian Ocean, driven by the anticyclonic circulation at the South Indian Ocean high-pressure; and the activity of mid-latitude cyclones, in addition to continental heating, govern the position and strength of the South Indian Ocean Convergence Zone [8]. During austral winter, when the sub-tropical high-pressure systems migrate northward over the southern African landmasses, large-scale subsidence is a major synoptic phenomenon associated with suppressed rainfall in the subcontinent. Variation in the position and strength of the subtropical ridges also influences SST in the adjacent oceans [17] and moisture transport [18].

A common method to characterize large-scale modes of atmospheric circulation in a given in region in the forms of physically interpretable recurrent patterns (circulation types) and investigate the probability of specific weather event to be associated with the recurrent patterns is weather typing with obliquely rotated principal component analysis (PCA) $[19,20]$. Thus this study uses the obliquely rotated PCA on the T-mode matrix (variable is time series and observation is grid points) of a field that explains atmospheric circulation [21] to characterize the synoptic situations in Africa south of the equator linked to extreme wet and dry conditions in Mozambique. Statistical relationships between the circulation types (CTs) and low-frequency modes of variability in the southwest Indian Ocean were also 
investigated. The specification of the synoptic states linked to extremes in wet and dry conditions in Mozambique and how the CTs might be constrained by climatic modes will extend the predictability of rainfall in Mozambique at the synoptic scale, and thus can be of usage both for a local weather agency and policymakers in Mozambique. Also, statistical changes in the CTs since 1961 are investigated.

\section{Data and Methodology}

Sea level pressure (SLP); precipitation; precipitable water; specific humidity, and wind vectors at $850 \mathrm{hPa}$ data sets are obtained from the NCEP-NCAR reanalysis [21]. The horizontal resolution of the data sets is $2.5^{\circ}$ longitude and latitude. The precipitation data set is obtained at a Gaussian grid type and interpolated to a $0.5^{\circ}$ longitude and latitude using the

102 First order conservative remapping. The temporal resolution of the data sets is daily from 1031961 to 2020. Precipitation data set from the Climate Prediction Center [22] obtained at a $1040.5^{\circ}$ longitude and latitude is used to validate the NCEP-NCAR precipitation data set for the 1981-2010 period.

The spatial extent for the circulation typing is $0^{\circ}-50.25^{\circ} \mathrm{S}$ and $5.75^{\circ} \mathrm{E}-55.25^{\circ} \mathrm{E}$. The

107 adjacent oceans are added since they act as moisture sources to the mainland. Obliquely 108 rotated PCA applied to the gridded SLP data set from 1961-2020 and represented in the Tmode structure is used to classify the CTs [20]. The relationship between the daily time series

110 is achieved with the correlation matrix. Singular value decomposition is used to factorize the

111 correlation matrix to obtain the eigenvectors, eigenvalues, and PC scores. The eigenvectors 112 are time series and they localize in time the input (spatial) patterns captured by the PC scores 
113 [23]. The eigenvectors are weighted with their corresponding eigenvalues making them

114 longer than a unit length, henceforth referred to as loadings [24]. Components with separated

115 eigenvalues are retained in line with the philosophy of [25]. However, since the subsequent 116 steps involve rotating the PCs, the recommendation of [25] might be trivial, and [26]

117 explained that components with low eigenvalues might contain meaningful patterns. Thus the 118 recommendation of [20] was followed: which ensured that the added new components, after 119 components with separated eigenvalues are retained, have not been delineated by previously 120 retained components, and this was typically assessed by a low congruence coefficient 121 between the scores and a visual inspection of the patterns [23]. The Promax routine, applied 122 at a power of 2 , is used to obliquely rotate the retained components [20]. The oblique rotation 123 eliminates orthogonality constraint and maximizes the number of near-zero loadings so that 124 each component clusters a unique number of days with a similar input pattern [27]. The 125 absolute value of the loadings presents an important signal and threshold values within the 126 range of 0.2-0.35 depending on the sample size can be used to separate the components [28]. $127 \pm 0.2$ is used in this paper to cluster the loadings under each component to positive loadings 128 and negative loadings above the 0.2 threshold - this step increases the weather coherency 129 between the days clustered under a given class; thus each retained component forms two 130 classes and the mean SLP of the days in each class is the CT.

131 CTs associated with heavy wet days and extreme dry events in Mozambique are selected 132 using equations (1) and (2). Heavy wet days is defined as the count of days with daily rainfall 133 estimates greater than the 95 percentile rainfall values averaged over Mozambique and 134 extreme dry days is defined as the count of days with daily rainfall estimate less than the 5 135 percentile rainfall value averaged over Mozambique. 


$$
P_{d i}=\frac{d_{i}}{N_{i}} \times 100 \quad i=1 \ldots n
$$

(1)

$$
P_{w i}=\frac{w_{i}}{N_{i}} \times 100 \quad i=1
$$

$141 P_{d i}$ is the percentage of extreme dry days for a given $\mathrm{CT}, d_{i}$ is the total number of

142 extreme dry days for the CT and $N_{i}$ is the total number of days clustered under the CT in

143 question. $P_{w i}$ is the percentage of heavy wet days in a given CT and $w_{i}$ is the total number of

144 heavy wet days for the CT, and $\mathrm{n}$ is the total number of classified CTs. After the wet day and 145 dry day probabilities are calculated for all CTs, a 90 percentile threshold is defined for $P_{d i}$ 146 and $P_{w i}$ and CTs beyond the thresholds are designated to be associated with extreme events 147 in Mozambique.

148 It is important to note that since CTs are inherently fuzzy and are not confined to occur at 149 a specific season (though they might be dominant at specific season(s)), the complete seasons 150 are used for the classification. However, the monthly cycle and the mean persistence days of 151 the selected CTs are analyzed. Composites of moisture flux at $850 \mathrm{hPa}$ (i.e. product of 152 specific humidity and wind speed) and precipitable water are used to further analyze the CTs 153 selected to be associated with extreme wet and dry conditions in Mozambique. The $850 \mathrm{hPa}$ 154 height is selected in analyzing moisture fluxes since it is the height above the eastern escarpment. The Nino3.4 Index and the IOD index are obtained from

156 https://psl.noaa.gov/gcos_wgsp/Timeseries/DMI/. The SAM index is obtained from

157 https://climatedataguide.ucar.edu/climate-data/marshall-southern-annular-mode-sam-index-

158 station-based. The indices are obtained for the 1961-2020 period. The SIOD index (SDI) is 159 calculated as the difference between SST anomalies at the western part $\left(55^{\circ} \mathrm{E}-65^{\circ} \mathrm{E} ; 37^{\circ} \mathrm{S}\right.$ - 
161 defined by [9]. The index is also calculated for the 1961-2020 period. Since each retained

162 component can exhibit a physically interpretable dipole [23] with each dipole represented by

163 the CT obtained from the mean SLP in a class (i.e. cluster of positive/negative loadings above 164 the 0.2 threshold); the annual and seasonal mean of the time series (loadings) under each retained component for the selected CTs are related to the annual and seasonal mean of the

166 climatic mode indices, respectively, using correlation analysis for the 1961-2020 period. A

167 positive correlation coefficient $(R)$ implies that the positive phase of the climatic mode is 168 related to the positive (dipole) phase of the component in question and a negative correlation 169 implies that the positive phase of the climatic mode is rather related to the negative (dipole) 170 phase of the component and vice versa. Statistical significance of the correlation is done at a $17195 \%$ confidence level using the Kendall-Tau test which is non-parametric. Also, the linear 172 trend in the annual frequency of occurrence of the CTs are investigated for the 1961-2020 period and a test for statistical significance of linear trend is done using the Mann-Kendall test at a 95\% confidence level. Correlation analysis is equally used to investigate the relationship between the annual frequency of occurrence of the selected (wet) CTs and the 176 climatic modes.

\section{Results}

\section{$\underline{3.1 \text { Seasonal rainfall climatology in Mozambique }}$}

Fig. 1 (top panel) shows the seasonal rainfall climatology in Mozambique. Austral summer (DJF) is relatively the wettest season and austral winter (JJA) is relatively the driest season. For the transition seasons, austral spring ( $\mathrm{SON}$ ) is relatively drier compared to austral 
more rainfall than the southern region. Also during austral winter, from the $\mathrm{CPC}$ data set, the

185 northern and western regions are relatively drier compared to the east-central and 186 southeastern regions. On the spatial scale, there is better agreement between the CPC and

187 NCEP-NCAR data sets for the wet seasons. However, for the dry seasons, relatively NCEP188 NCAR produces too much rainfall in parts of the central and southern domains of 189 Mozambique. Averaged over Mozambique, NCEP-NCAR relatively overestimates 190 precipitation for all months except for the January-March months (Fig. 1, bottom panel).

By retaining 9 components $18 \mathrm{CTs}$ were classified in Africa south of the equator. Fig. 2a shows the CTs and Fig. $2 \mathrm{~b}$ shows the rainfall composite associated with the CTs in the regional context of Mozambique. Each CT in Fig. 2a is representative of a synoptic situation in the study region and the spatial distribution and intensity of rainfall associated with the mechanism of the CTs are presented in Fig. 2b. Based on equations (1) and 2, the wet and dry

199 CTs in Mozambique are highlighted by the blue and red frames, respectively. CT5+, CT6+,

200 CT7+, and CT9+ have the highest probability to be associated with extreme rainfall in large parts of Mozambique. Relatively, the probability of extreme wet days was found to be highest under CT5+. On the other hand, CT5-, CT6-, and CT9- were found to have a high probability to be associated with extreme dry days in Mozambique. Relatively the probability of extreme 204 dry days was found to be highest under CT6-. Fig. 2b shows that for the aforementioned wet/dry CTs; rainfall enhancement/suppression in Mozambique is evident during the active periods of the CTs. From Fig. 2a, generally, for the wet/dry CTs cyclonic/anticyclonic 
the (tropical) oceans, regions with cyclonic/anticyclonic circulation in synoptic systems can

209 be associated with enhanced/diminished convective activity [29]. Cyclonic activity over the

210 tropical ocean is also related to warm SST.

211 Fig. 3a shows the annual cycle of the wet CTs (right panels) and dry CTs (left panels).

212 The wet CTs are generally dominant during late austral spring (November) to early austral

213 autumn. For the dry CTs, CT5- and CT6- are generally dominant from late austral autumn

214 (April/May) to early austral spring (September/October). CT9- is an austral spring CT,

215 prevailing exclusively in October. The prevalent period of the wet/dry CTs is also when SST

216 is warm/cold at the south India Ocean, and continental heating (reflected by the low-pressure

217 system on the landmasses) is enhanced/diminished over the landmasses. A plausible reason

218 why cyclonic circulation prevails over the landmasses, but anticyclonic activity prevails over

219 the Mozambique Channel in CT9- despite its dominance during austral spring is due to the

220 high heat capacity of ocean waters that makes it warm slowly [30]; this also explains why the

221 magnitude cyclonic activity in the Mozambique Channel is highest under CT9+ since early

222 austral autumn is likely to be when SST will peak in the Mozambique Channel. Fig. 3b shows

223 that the dominant periods of the CTs are when they are likely to persist for a longer time.

224 Generally, the persistent time of the wet/dry CTs can be up to 5 days and this strengthens the

225 probability of the CTs being associated with extremes in Mozambique since it is the

226 persistent time of a CT that determines if its rain-bearing or rain-suppressing characteristics

227 will be expressed in a local climate.

Fig. 4 shows the composite of moisture flux at $850 \mathrm{hPa}$, SLP, and precipitable water for the wet CTs (right panels) and dry CTs (left panels). In the deep tropical oceans $\left(0-10^{\circ} \mathrm{S}\right)$ there is no significant variation in the amounts of precipitable water for both the wet and dry

231 CTs. However, for the wet/dry CTs precipitable water is relatively enhanced/diminished over 
232 the landmasses of southern Africa and the southwest Indian Ocean. Except for CT6- and 233 apparently, CT5-, a notable difference between moisture advection for the wet/dry CTs is the 234 presence of southeast/southwest winds over the southwest Indian Ocean waters, south of 235 Madagascar, between about $30^{\circ} \mathrm{E}-45^{\circ} \mathrm{E}$. Due to the high topography of Madagascar and 236 inadequate proximity, southeast wind emanating from $45^{\circ} \mathrm{E}$ and eastward is trivial to moisture transport and rainfall formation in Mozambique.

238 For the dry CTs, the relatively wet condition at eastern regions of Mozambique under the 239 rainfall composite of CT6- and apparently under CT5- (Fig. 2b) can be attributed to the 240 southeast winds that drive moisture to the eastern regions through the Agulhas current and the 241 Mozambique Channel. A major difference in moisture transport between CT6- and CT5242 from Fig. 4 is that during CT6- westerly winds are adjusted to southeast winds (between 243 about $30^{\circ} \mathrm{E}-40^{\circ} \mathrm{E}$ ) by the activity of the South Atlantic Ocean anticyclone, thus driving 244 moisture onshore through the warm Agulhas and Mozambique current; while during CT5245 westerlies dominate across the Agulhas region and southeast winds, which are partially 246 obstructed by the high Madagascar topography, are rather driven by the activity of the south 247 India Ocean high-pressure. Thus under CT6- more moisture from southwest Indian reaches 248 Mozambique, relatively, resulting to why in Fig. 2b the eastern regions of Mozambique are 249 relatively wetter under CT6- and a zonal rainfall dipole structure is more expressed. Also, 250 under CT5- and CT6- the central-west and southwestern parts of Mozambique are dry; the 251 dominance of high-pressure system over a large part of the southern regions of Mozambique 252 during these CTs reflects that during austral winter, dryness in the southwestern parts of 253 Mozambique can be attributed to large-scale subsidence. CT9- indicates a meridional dipole 254 structure of rainfall whereby the northern regions are relatively drier. The mechanism beyond 255 this rainfall structure is not clear but the absence of southeast winds driving moisture through 256 the Agulhas current and the Mozambique Channel can be a significant reason since easterlies 
that reach northern Mozambique under this synoptic state might be relatively dry given that the advected moisture towards northern Mozambique is conceivably dropped off the high topography of Madagascar.

For the wet CTs, CT5+, and CT6+ indicates enhanced cyclonic activity from the tropical to the southwest Indian Ocean and a weaker state of the western branch of the south Indian

262 Ocean high-pressure, thus precipitable water is enhanced not only in the Mozambique 263 Channel but also towards the Agulhas current. The moisture that reaches Mozambique from 264 the southwest Indian Ocean during these CTs results from the activity of the South Atlantic 265 Ocean anticyclone, ridging south of South Africa - westerly moisture fluxes are adjusted to 266 southeast moisture fluxes driving abundant moisture onshore of Mozambique - as a result, 267 widespread rainfall is evident in Mozambique during these CTs (Fig. 2b). Under CT7+ and 268 CT9+, anticyclonic circulation at the western branch of the south Indian high-pressure is active in driving moisture onshore through the warm Mozambique current - especially during CT7+. From Fig. 2b, it is evident that under CT5+ and CT6+ rainfall is relatively widespread in Mozambique but under CT7+ and CT9+ enhanced rainfall is rather evident mostly in the northern regions of Mozambique. A plausible reason for the differing spatial rainfall patterns is that during $\mathrm{CT} 5+$ and $\mathrm{CT} 6+$, in addition to the abundant moisture that is advected onshore by southeast winds through the activity of the South Atlantic Ocean anticyclone ridging south of South Africa and the enhanced moisture advection towards northern Mozambique (unobstructed by the Madagascar topography) from the tropical Indian Ocean by northeast winds, a low-pressure system (an indication of upward vertical motion) is widespread over Mozambique (c.f. Fig. 2a). However, during CT7+ and CT9+ the low-pressure system is rather more prevalent in the northern regions. Also under CT9+, since the cyclonic system in

280 the Mozambique Channel partly adjusts easterlies to westerlies, less moisture relatively 281 reaches the southern parts of Mozambique. Generally, widespread warming of the southwest 
Indian Ocean, coupled with onshore moisture advection by southeast winds resulting from

283 the activity of the South Atlantic Ocean anticyclone, ridging south of South Africa, favor 284 widespread rainfall in Mozambique; while enhanced warming of the Mozambique Channel, 285 coupled with moisture driven by southeast winds through the activity of the western branch 286 of the south Indian Ocean high-pressure ridging into the eastern regions of southern Africa, rather favors enhanced rainfall at the northern parts of Mozambique.

This section examines if some major low-frequency modes of variability in the south Indian Ocean are related to the CTs selected to be associated with extreme wet and dry conditions in Mozambique. Fig. 3 shows the time series of the selected CTs and the climatic modes that they are statistically related to based on correlation analysis of the annual mean values of the loadings of each Type and the indices of the climatic modes. Thus the correlation analysis probes if years with above/below average value of a given climatic mode index can be related to above/below average amplitude of a given Type. Table 1 shows the correlation analysis done at a seasonal scale. Types that are statistically related to the climatic modes are reported in the table and the sign of the correlation coefficient is given as well.

298 Table 2 shows correlation analysis between the indices of the climatic modes and the annual frequency of occurrence of the wet CTs. Only correlations that are statistically significant at a 95\% confidence level are reported.

First, based on correlation analysis, for the 1961-2020 period, a statistically significant 302 relationship was found between Type 5 (i.e. CT5+/CT5-) and the Nino3.4 index $(R=0.30)$.

303 The positive correlation implies that the above-average Nino3.4 Index (i.e. positive phase of 304 ENSO) is related to CT5+ and below-average Nino3.4 index (i.e. negative phase of ENSO) is related to CT5-. This relationship can be due to the enhanced warming/cooling of the south 
Indian Ocean during the positive/negative phases of the ENSO and Type 5. On the seasonal

307 scale, Table 1 shows that this relationship is strongest during the austral autumn season when

308 SST is likely to peak in the southwest Indian Ocean (i.e. early austral autumn). El Niño is

309 expected to weaken the south Indian Ocean high-pressure [8] and this is evident during

310 CT5+, and vice versa for La Niña (c.f. Fig. 2a). Type 5 tend to exhibit some seasonality (c.f.

311 Fig. 3a), and while its occurrence and synoptic features are not dependent on ENSO, the

312 results here suggest that during El Niño the synoptic state of CT5+ is likely to persist or

313 amplify; but with enhanced warming of the south Indian Ocean, easterly moisture fluxes

314 might be further adjusted to westerly leading to the weakening of onshore moisture advection

315 to southern African landmasses. Thus it is conceivable that despite the direct relationship

316 between ENSO and Type 5, ENSO might still have the capability of adjusting the circulation

317 dynamics of Type 5 so that CT5+ might become dry. This can be justified from the

318 statistically significant correlation from Table 2, showing that years with above-average

319 Nino3.4 index can be associated with below-average frequency of occurrence of CT5+.

320 Moreover, a strong dynamical linkage was found between CT5- and CT7+; during austral

321 summer, the occurrence of CT5- on a given day is usually followed by CT7+ on the same day

322 - both CTs tend to co-occur and the synoptic state of CT7+ was found to be prevalent during

323 strong La Niña. Hence during austral summer, the relationship between CT5- and below-

324 average Nino3.4 index (La Niña) can usher in CT7+ which is associated with enhanced

325 anticyclonic circulation at the western branch of the Mascarene high (as observed during

326 strong La Niña years). Strong El Niño years might imply (i) a weakening of onshore moisture

327 advection by the south Indian Ocean high-pressure as evident in CT5+, (ii) persistent and

328 amplification of cyclonic circulation in the south Indian Ocean; which are likely to further

329 reduce onshore moisture advection and equally weaken convergence into the Angola low.

330 Here it is also shown that the activity of the South Atlantic Ocean anticyclone might still 
counteract the weakened advection by southeast winds resulting from the south Indian Ocean

332 high-pressure. Thus it is the strength of the ENSO event to constrain and adjust regional 333 atmospheric circulations that will ultimately decide the southern African precipitation

334 response. Trend analysis of Type 5 for the 1961-2020 period suggests that it is shifting 335 towards positive polarity. Fig. 6 shows that the frequency of occurrence of CT5+/CT5- has a 336 positive/negative trend that is statistically significant at a 95\% confidence level 337 (pvalue $<0.05$ ). Moreover, the days of persistence of CT5 + for the climatological normal of 1991-2020 were found to have increased relative to $1961-1990$ by 2 days.

Type 6 (i.e. CT6+/CT6-) was found to be related to the SDI index $(R=0.39)$. The 340 positive correlation implies that the positive/negative phase of the SIOD is related to the 341 positive/negative phase of Type 6. Fig. 5 shows the time series of the SDI and the Type 6 for 342 the 1961-2020 period. On the seasonal scale, this relationship is positive and statistically 343 significant for the austral spring and summer months. During the positive SIOD event, 344 anomalous warming (cyclonic activity) of the southwest Indian Ocean, coupled with 345 southeast winds, is the major mechanism through which a positive SIOD brings above346 average rainfall in large parts of south-central Africa [13]. Enhanced cyclonic activity and 347 precipitable water are evident in the southwest Indian Ocean during CT6+ and this makes the 348 relationship physically realistic so that it is conceivable that through the atmospheric 349 circulation dynamics of CT6+ the positive SIOD can lead to above-average rainfall in large 350 parts of Mozambique. Table 2 shows, that years with above-average SDI can be associated 351 with above-average frequency of occurrence of CT6+. Also, at the seasonal scale, CT6+ is 352 positively related to the Nino3.4 index during the austral summer and autumn months, similar 353 to $\mathrm{CT} 5+$. This relationship is physically realistic since CT6+/CT6- is associated with 354 enhanced cyclonic/anti-cyclonic activity from the tropical to the southwest Indian Ocean 
which might be expected during periods with above-average/below-average Nino3.4 Index. A reason why CT6+ is related to Nino3.4 index during austral summer but CT5- is not can be due to the synoptic nature of CT5+ that might require a peak in SST (usually attained during early austral autumn) in the basin, to enable enhanced suppression of the western branch of the Mascarene high. Changes in the polarity and frequency of occurrence of Type 6 are not statistically significant for the 1961-2020 period (Fig. 5 and Fig. 6).

Type 7 (i.e. CT7+/CT7-) was found to be related to the SAM $(R=0.33)$. The positive correlation implies that the positive/negative phase of SAM is related to the positive/negative phase of Type 7. The positive/negative phase of the SAM implies SLP increase/decrease in the mid-latitudes. This is due to the mid-latitude cyclones tracking southward/northward during the positive/negative phase of the SAM. The relationship is most expressed during austral summer when CT7+ dominates (Table 1). Since during positive SAM event, SLP increases in the mid-latitudes, this might favor anomalous anti-cyclonic circulation at the south Indian Ocean high-pressure. Table 2 shows that there is a positive correlation between the SAM and the frequency of occurrence of CT7+. Implying that positive SAM favors the occurrence of CT7+ and vice versa. Thus the results here suggest that when the mid-latitude cyclones deepen in the high southern latitudes, the south Indian Ocean high-pressure strengthens as also found by [31], favoring onshore moisture transport to Mozambique by southeast winds. However, from Table 2, there is a negative relationship between the

374 frequency of occurrence of CT5+ and the SAM, implying that unlike in CT7+, SLP increase

375 in the mid-latitudes during positive SAM might constrain the frequency of occurrence of 376 CT5+. Also during austral winter, CT5- can be related to the negative phase of the SAM and this is physically realistic given the enhanced westerlies, south of South Africa during CT5-; i.e. a prevalent synoptic state during negative SAM associated with northward track of the 
mid-latitude cyclones. From Fig. 5, Type 7 is shifting towards a positive polarity since 1961, and Fig. 6 shows a positive trend in the frequency of occurrence of CT7+. However, a notable decrease of up to 3 days was found in its persistent days in the 1991-2020 climatological period relative to 1961-1990; a possible reason might be attributed to the extent to which southwest Indian is warming under climate change [32,33].

Finally, the IOD is related to both Type $5(R=0.43)$ and Type $9(R=0.48)$. The time series of the IOD, Type 5, and Type 9 can be seen in Fig. 5. The relationships are generally more expressed during the winter and spring months. The relationship implies that positive/negative IOD which implies warming/cooling of the western tropical Indian Ocean is related to the positive/negative phases of Type 5 and Type 9. Physically, CT9+ indicates strong cyclonic activity concentrated in the tropical south Indian and to a lesser extent, CT5+ shows a similar result and vice versa for their negative phases (c.f. Fig. 2a). Hence during a positive IOD, the circulation dynamics of CT9+ and CT5+ will play vital roles in how Mozambique rainfall will respond. In the case of a strong positive IOD, the implication of CT9+ might imply that at least large parts of southern Mozambique will be dry relative to the northern regions since easterly moisture fluxes will be adjusted to westerly. The relationship between positive IOD and CT9+ equally suggest that in the case a strong positive IOD amplify the low-pressure system in the Mozambique Channel (i.e. the Mozambique Channel trough) that is active during CT9+, then rainfall reduction might be expected in parts of southern Africa since easterly moisture fluxes will be adjusted to westerlies by the cyclonic system, limiting onshore moisture advection to parts of southern Africa. No direct relationship was found between IOD and the frequency of occurrence of CT9+ and this might

401 be due to the tendency of CT9+ to prevail during late austral summer and, and austral autumn 402 months when the IOD has already possibly decayed. A negative relationship was found 
between IOD and the frequency of occurrence of CT9-, suggesting that the positive IOD can

404

405

406

407

408

409

410

411

412

413

414

415

416

417

418

419

420

421

422

423 constrain CT9- as a result of the warming of the (tropical and) southwest Indian Ocean. Nevertheless, from Table 2, there is also a negative relationship between the frequency of occurrence of the IOD and CT5+, suggesting that similar to El Niño, deepening of cyclonic activity in the basin can constrain CT5+. While Type 9 shows a shift to a positive polarity since 1961, no trend was detected in the frequency of occurrence of CT9+, rather a negative trend was found for CT9- (Fig. 5 and Fig. 6).

\section{Discussion and conclusions}

In this study, circulation typing was used to identify synoptic situations in Africa south of the equator that favor extreme wet and dry conditions in Mozambique. Also, the relationship between the CTs and major climatic modes in the south Indian Ocean was examined and changes in the polarity, frequency of occurrence, and persistence time of the CTs since 1961 were equally analyzed. Obliquely rotated PCA applied to the T-mode matrix of SLP field from NCEP-NCAR for the 1961-2020 period was used to classify the CTs. This clustering approach introduced by [20] has proved to be a useful tool in reproducing predefined CTs (known a priori) in a given region $[23,39]$, which might be the best way to validate the efficiency of a clustering approach. According to [39] "The T-mode analysis can lead to the determination of frequent synoptic situations, improving the basic knowledge essential to weather forecasting, among other things. The application of such a tool to a wide range of processes, ranging from the daily synoptic developments to the monthly or annual mean developments is valuable for an ample set of atmospheric processes, including both daily variability and climate fluctuations and change". The aforementioned qualities of the rotated T-mode PCA when used for circulation typing as highlighted by [39], have been widely 
427 tested by the author, in Africa south of the equator, (e.g. [40]) and were found to be true.

428 Thus despite that this clustering approach is still unpopular in the study region, in the author's

429 opinion, it deserves further attention as a promising clustering approach that both embraces

430 the fuzziness of atmospheric circulation types and can yield physically meaningful

431 classifications that can be physically validated from synoptic situations known a priori from

432 studies based on dynamical simulations in the study region. The author also found that the

433 precipitation response to atmospheric circulation patterns differs in line with the climate and

434 location of the local target region. Thus each of the $18 \mathrm{CT}$ s can be relevant depending on the

435 research goal and local climate of interest, considering the heterogeneity of the climate of

436 southern Africa. In this study, the author extends the applicability of the rotated T-mode PCA

437 by analyzing the climatic modes that might be linked to an ample set of CTs linked to

438 extreme wet and dry events in Mozambique.

439 Four synoptic situations were identified to be associated with above-average rainfall in

440 Mozambique - two brings wide-spread rainfall in Mozambique and the other two seem to be

441 associated with above-average rainfall mostly in the northern regions of Mozambique.

442 Generally, enhanced precipitable water at the southwest Indian Ocean coupled with southeast

443 winds were found to favor extreme rainfall in Mozambique. This is in agreement with the

444 findings of $[13,18,20,34]$. However, the major difference between the wet CTs associated

445 with widespread rainfall in Mozambique and the wet CTs associated with a dipole-like

446 structure of rainfall is that for the former, (i) wide-spread warming (cyclonic activity) was

447 evident in the southwest Indian Ocean, (ii) widespread low-pressure system was evident on

448 Mozambique landmass, (iii) and southeast winds were due to the activity of the South

449 Atlantic Ocean anticyclone, ridging south of South Africa [34]; while for the later, (i)

450 cyclonic activity was concentrated at the Mozambique Channel, (ii) low-pressure system was

451 focused at the northern parts of Mozambique, (iii) southeast winds were due to the activity of 
the south Indian Ocean high-pressure, ridging into the eastern parts of southern Africa [18]. It

453 is equally interesting that the wet CTs are dominant during late austral spring to early austral

454 autumn when the Indian Ocean is generally warm and continental heating is active on the

455 landmasses.

Three CTs were found to be associated with dry conditions in Mozambique - two of the

457 CTs indicate a (zonal) dipole structure of rainfall whereby the southwestern regions are 458 relatively drier compared to the northeastern regions; the other dry CT shows rather a meridional dipole structure of rainfall whereby the northern regions are drier than the

460 southern regions. Generally, during austral winter, when the cross-equatorial northeast winds

461 are inactive, southeast winds are predominantly the source of moisture to Mozambique and

462 the high topography of Madagascar seems to play a vital role in the meridional dipole-like structure of rainfall. In the presence of southeast winds in the southwest Indian Ocean, south of Madagascar, between $30^{\circ} \mathrm{E}-45^{\circ} \mathrm{E}$, the eastern regions of Mozambique are relatively wet while the western regions are dry due to large-scale subsidence [35]. But when westerly wind

466 prevails in the southwest Indian Ocean, south of Madagascar, the northern regions are driest

467 and this might be linked to the advection of dry air (with its moisture dropped off the east coast of Madagascar) by southeast winds to northern Mozambique.

$[36,37]$ highlighted that climatic modes such as ENSO can alter regional patterns of atmospheric circulation; here it was found that the selected CTs are significantly related to major climatic modes in the south Indian Ocean thus revealing the basic atmospheric 472 circulation patterns through which the climatic modes might impact rainfall variability in 473 Mozambique. The IOD and the ENSO which are associated with warming/cooling of the 474 (western) tropical Indian Ocean during their positive/negative phases were found to be related 475 to input spatial patterns that featured enhanced cyclonic/anticyclonic activity in the (western) 
tropical Indian Ocean during their positive/negative phases. Both input patterns indicate a

477 shift towards positive polarity since 1961, with the positive phase of the input pattern related to El Niño showing a positive trend in the frequency of occurrence since 1961 and an increase in days of persistence for the period of 1991-2020 relative to 1961-1990. This suggests that cyclonic activity might be increasing in the tropical western Indian Ocean under the activity of CT5+. [38] identified an increase in the frequency of category 5 storms since 1989 in the south Indian Ocean. Moreover, it is not inevitable that greenhouse gas-induced climate change and its influence on global SST might be linked to the increasing trend in the persistence and frequency of occurrence of CT5+ and the author intends to investigate this in further works.

The synoptic state that is associated with an enhanced cyclonic activity from the tropical Indian Ocean, towards the Agulhas current, was found to the related to the positive phase of the SIOD. The spatial pattern of this synoptic state is in agreement with patterns of atmospheric circulation indicated by [13] that is prevalent during positive SIOD events based on enhanced cyclonic activity at the southwest Indian Ocean, coupled with southeast winds. The positive phase of the SAM was found to be related to the synoptic state associated with the intensification of the south Indian Ocean high-pressure [31]. While it was found that the frequency of occurrence of this synoptic state (i.e. CT7+) has increased since 1961, its days of persistence have significantly decreased, possibly due to the counteracting effect of

495 the warming of the southwest Indian Ocean [33]. At specific seasons, some of the CTs were equally found to be related to some of the aforementioned climatic modes. 


\section{Declarations}

$501 \quad$ Conflict of interest: There are no conflicts of interest in this paper.

502 Funding statement: This research received no specific grant from any funding agency in 503 the public, commercial, or not-for-profit sectors.

\section{References}

506 1. Sidley, Pat. Floods in Southern Africa result in cholera outbreak and displacement.

507 BMJ (Clinical research ed.). 336, 471 (2008).

508 2. IPCC (2013): Climate Change. The Physical Science Basis. Contribution of Working

509 Group I to the Fifth Assessment Report of the Intergovernmental Panel on Climate Change

510 [Stocker TF, Qin D, Plattner GK, Tignor M, Allen SK, Boschung J, Nauels A, Xia Y, Bex V,

511 Midgley PM (eds.)]. Cambridge University Press, Cambridge, United Kingdom and New

512 York, NY, USA, 1535 pp (2013).

513 3. Chikoore, H., Vermeulen, J. H. \& Jury, M. R. Tropical cyclones in the Mozambique

514 Channel: January-March 2012. Natural Hazards. vol. 77, 2081-2095 (2015).

515 4. Ash, K. \& Matyas, C. J. The influences of ENSO and the Subtropical Indian Ocean

516 Dipole on tropical cyclone trajectories in the South Indian Ocean. Int. J. Climatol. 32, 41-56

517 (2012).

518 5. Jury, M. R. A preliminary study of climatological associations and characteristics of

519 tropical cyclones in the SW Indian Ocean. Meteorol. Atmos. Phys. 51, 101-115 (1993). 
6. Klinman, M. G. \& Reason, C. J. C. On the peculiar storm track of TC Favio during the 2006-2007 Southwest Indian Ocean tropical cyclone season and relationships to ENSO. Meteorol. Atmos. Phys. 100, 233-242 (2008).

7. Ibebuchi, C. Can synoptic patterns influence the track and formation of tropical cyclones in the Mozambique Channel? Preprint, available at Research Square. Viewed 19 525 February 2021, DOI: 10.21203/rs.3.rs-200536/v1.

8. Cook, K. H. The South Indian Convergence Zone and Interannual Rainfall Variability over Southern Africa. J. Clim. 13, 3789-3804 (2000).(2000)013<3789:TSICZA>2.0.CO;2

9. Behera, S. K. \& Yamagata, T. Subtropical SST dipole events in the southern Indian Ocean. Geophys. Res. Lett. 28, 327-330 (2001).

10. Saji, N. H., Goswami, B. N., Vinayachandran, P. N., \& Yamagata, T. A dipole mode in the tropical Indian Ocean. Nature 401, 360-362 (1999).

11. Madden, R. A. \& Julian, P. R. Observations of the 40-50 day tropical oscillation-a review. Mon. Weather. Rev. 122, 814-837 (1994).

12. Thompson, D. W. J. \& Wallace J. M. Annular modes in the extratropical circulation.

Part I: Month-to-month variability. J. Clim. 13, 1000-1016 (2000). rainfall. Geophys. Res. Lett. 28, 2225-2228 (2001).

14. Luo, J., Zhang, R., Behera, S. K., Masumoto, Y., Jin, F., Lukas, R. \& Yamagata, T. Interaction between El Niño and extreme Indian Ocean dipole. J. Clim. 23, 726-742 (2010).

540 15. Yeshanew, A. \& Jury, M. R. North African climate variability, part 1: tropical 541 thermocline coupling, Theor. Appl. Climatol. 89, 25-36 (2007). 
544 17. Vigaud, N., Richard, Y., Rouault, M. \& Fauchereau, N. Moisture transport between 545 the South Atlantic Ocean and Southern Africa: relationships with summer rainfall and 546 associated dynamics. Clim. Dyn. 32, 113-123 (2009).

547 18.Lazenby, M. J., Todd, M. C. \& Wang, Y. Climate model simulation of the South 548 Indian Ocean Convergence Zone: mean state and variability. Clim. Res. 68, 59-71 (2016).

549 19. Compagnucci, R. H. \& Ruiz, N. E. On the interpretation of Principal Component 550 Analysis applied to meteorological data. In Proceedings of the Fifth International Meeting on 551 Statistical Climatology. Atmospheric Environmental Service of Canada: Toronto; 241-244 552 (1992).

20. Richman, M. B. Obliquely rotated Principal Components: an improved meteorological map typing technique? J Appl Meteorol. 20, 1145-1159 (1981).

21. Kalnay, E., et al. The NCEP/NCAR 40-year reanalysis project, Bull. Amer. Meteor. Soc. 77, 437-472 (1996).

22. Chen. M., et al. CPC Unified Gauge-based Analysis of Global Daily Precipitation, 558 Western Pacific Geophysics Meeting, Cairns, Australia, 29 July - 1 August (2008).

23. Compagnucci, R. H. \& Richman, M. B. Can principal component analysis provide 560 atmospheric circulation or teleconnection patterns? Int. J. Climatol. 28, 703-726 (2008).

561 24. Richman, M. B. \& Lamb, P. J. Climatic pattern analysis of three and seven-day 562 summer rainfall in the Central United States: some methodological considerations and 563 regionalization. J. Climate Appl. Meteo. 24, 1325-1343 (1985). 

of Empirical Orthogonal Functions. Mon. Wea. Rev. 110, 699-706 (1982).

566

26. Preisendorfer, R. W., Zwiers, F. W. \& Barnett, T. P. Foundations of principal

component selection rules. Scripps Institute of Oceanography, La Jolla, California, SIO Ref.

Series 81-4 (NTIS PB), 83-146613 (1981).

28. Richman, M. B. \& Gong, X. Relationships between the definition of the hyperplane

Western North Pacific. Part 1: spatial patterns and tropical cyclone characteristics. Mon.

Wea. Rev. 123, 1225-1246 (1995).

30. Gray, W.M. A global view of the origin of tropical disturbances and storms. Mon.

Wea. Rev. 96, 669-700 (1968).

31. Xue, F., Wang, H. \& He, J. Interannual variability of Mascarene High and Australian

High and their influence on the East Asian summer rainfall over East Asia

. Chin. Sci. Bull. 48, 492-497 (2003).

580

32 Morioka, Y., Takaya, K., Behera, S. K. \& Masumoto, Y. Local SST Impacts on the

581 Summertime Mascarene High Variability. J. Clim. 28, 2:678-694 (2015).

582 https://doi.org/10.1175/JCLI-D-14-00133.1

33. Vidya, P.J., Ravichandran M., Subeesh M. P., Chatterjee, S. \& Nuncio, M. Global 

on ridging Atlantic Ocean Anticyclone over South Africa. J. Clim. 31, 6175-6187 (2018).

35. Dedekind, Z., Engelbrecht, F. A. \& Merwe, J. Model simulations of rainfall over southern Africa and its eastern escarpment. Water SA 42, 129 (2016). http://dx.doi.org/10.4314/wsa.v42i1.13

36. Gray, W. M. \& Sheaffer, J. D. El Niño and QBO influences on tropical cyclone activity. Teleconnections linking worldwide climate anomalies. Glantz MH, Katz RW,

Nicholls N. (eds). Cambridge University Press: Cambridge, UK; 535 (1991). natural climate variability on tropical cyclones, and seasonal forecasts of tropical cyclone activity. Global perspectives on tropical cyclones: From science to mitigation, 2nd edn. Chan JCL, Kepert JD (eds). World Scientific: New York (2010).

38. Fitchett, J. M. Recent emergence of CAT5 tropical cyclones in the South Indian

40. Ibebuchi, C. Synoptic situations in Africa south of the equator linked to wet events in 604 Namibia; a case study with the February 2008 flood episode. Preprint, available at Research 605 Square. Viewed 20 April 2021, DOI: 10.21203/rs.3.rs-368816/v1. 
610 Table 1: Seasonal correlation between the loadings of the selected Types and the indices

611 of the climatic modes for the 1961-2020 period

612

\begin{tabular}{|l|l|l|l|c|}
\hline Climatic mode & \multicolumn{1}{|c|}{ DJF } & MAM & JJA & SON \\
\hline Nino3.4 & $(+)$ Type6 & $(+)$ Type5, (+)Type6 & - & - \\
\hline IOD & - & - & $(+)$ Type5, $(+)$ Type9 & $(+)$ Type9 \\
\hline SAM & $(+)$ Type7 & - & $(+)$ Type5 & - \\
\hline SIOD & $(+)$ Type6 & - & - & $(+)$ Type6 \\
\hline
\end{tabular}

613

614

615 Table 2: Correlation between the indices of the climatic modes and the annual frequency of

616 occurrence of the wet CTs for the 1961-2020 period

\begin{tabular}{|l|c|c|c|c|}
\hline Climatic mode & CT5+ & CT6 + & CT7+ & CT9+ \\
\hline Nino3.4 & -0.31 & - & - & - \\
\hline IOD & -0.36 & - & - & - \\
\hline SAM & -0.25 & - & +0.34 & - \\
\hline SIOD & - & +0.35 & - & - \\
\hline
\end{tabular}

617

$618 \quad$ Figures 


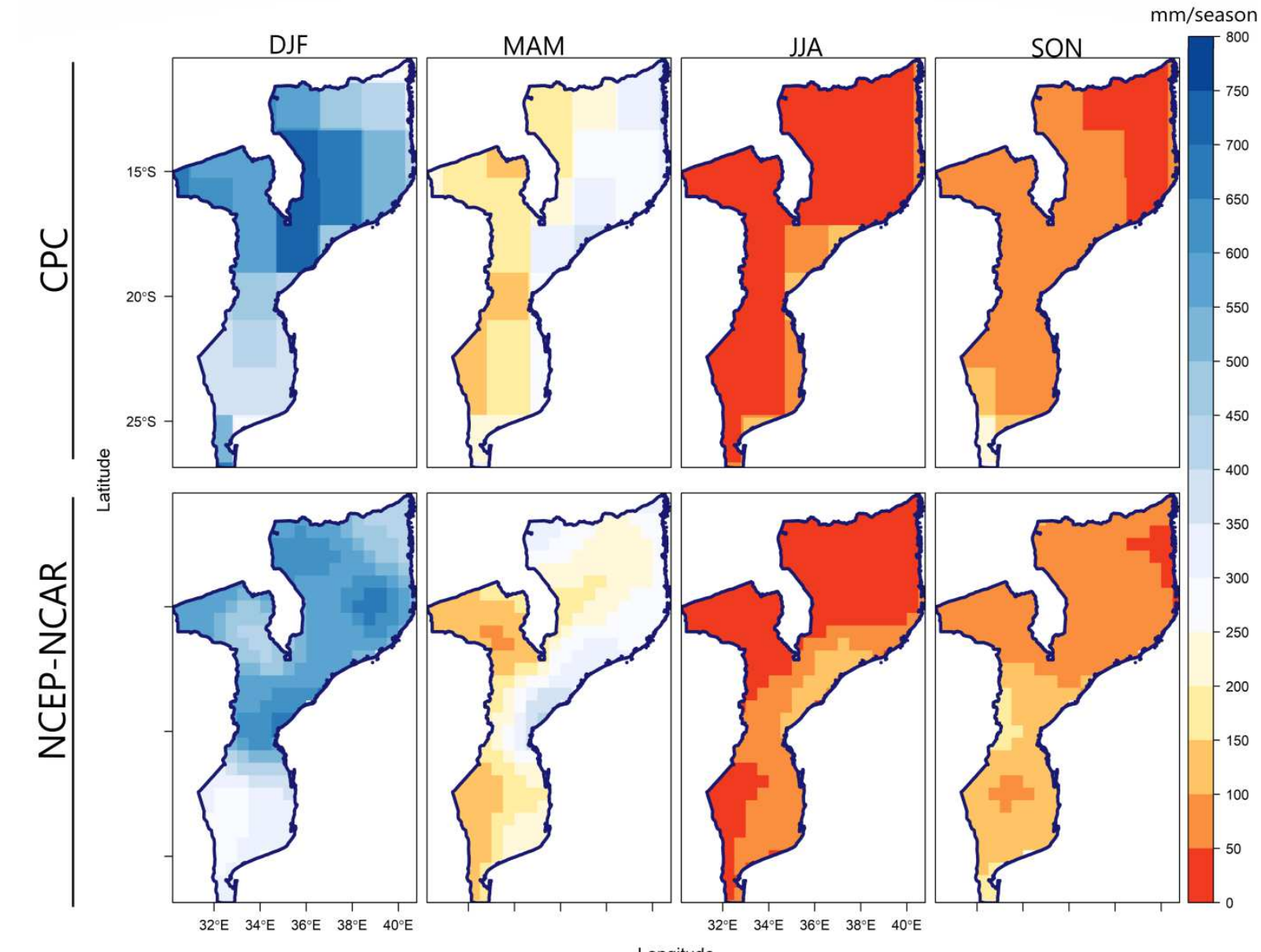

619

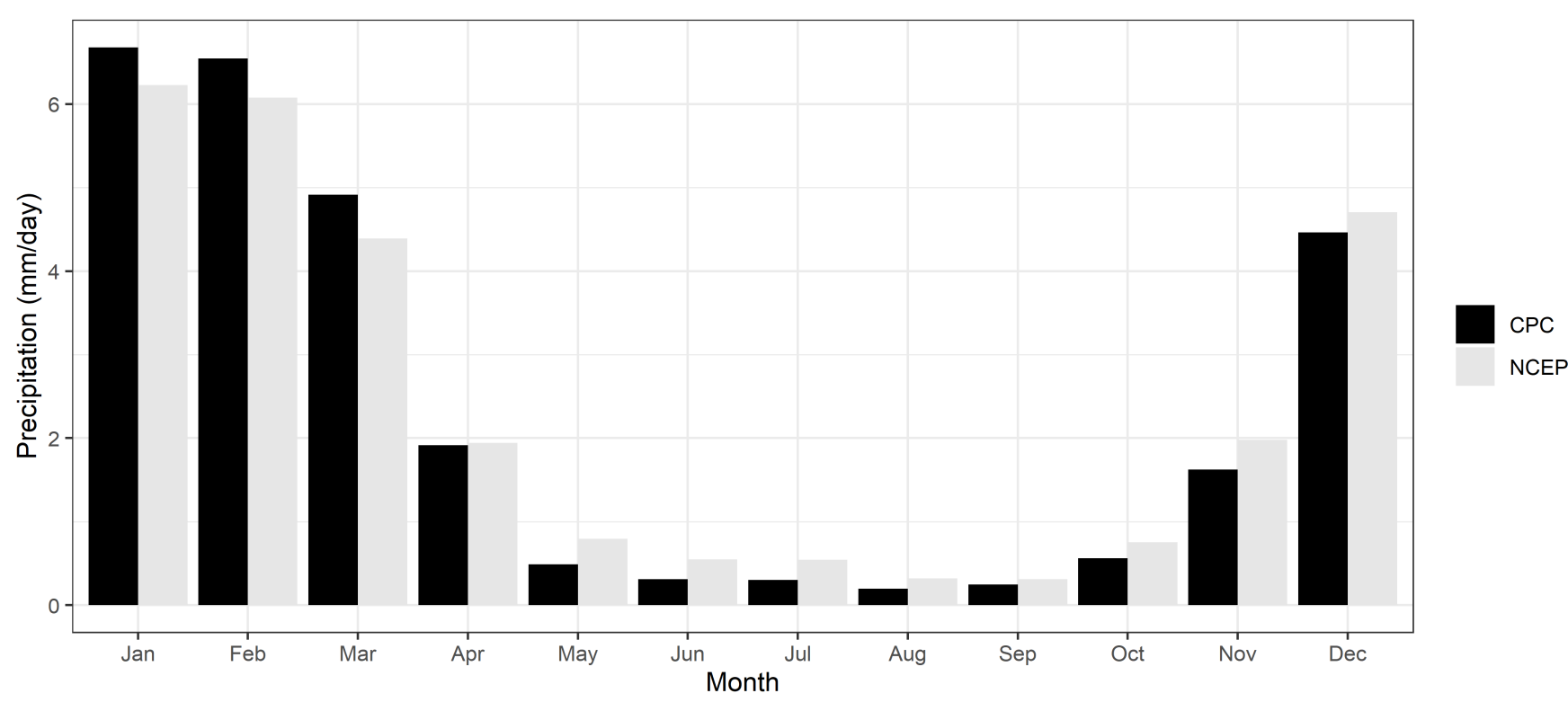

621 
622 Fig. 1: Seasonal rainfall climatology in Mozambique from the CPC and NCEP-NCAR

623 precipitation data sets (top panel) and the monthly cycle of precipitation in Mozambique from

624 the data sets.

625

626 a)
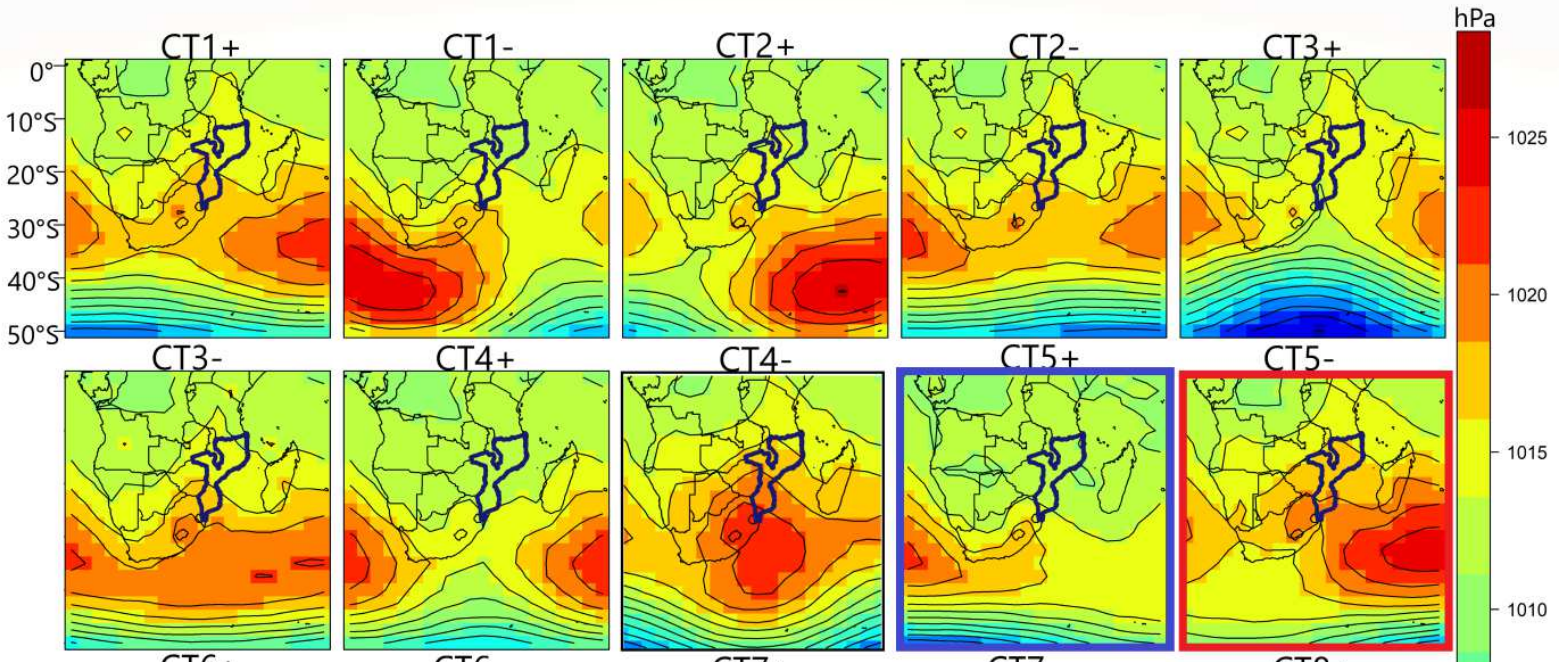

CT5-
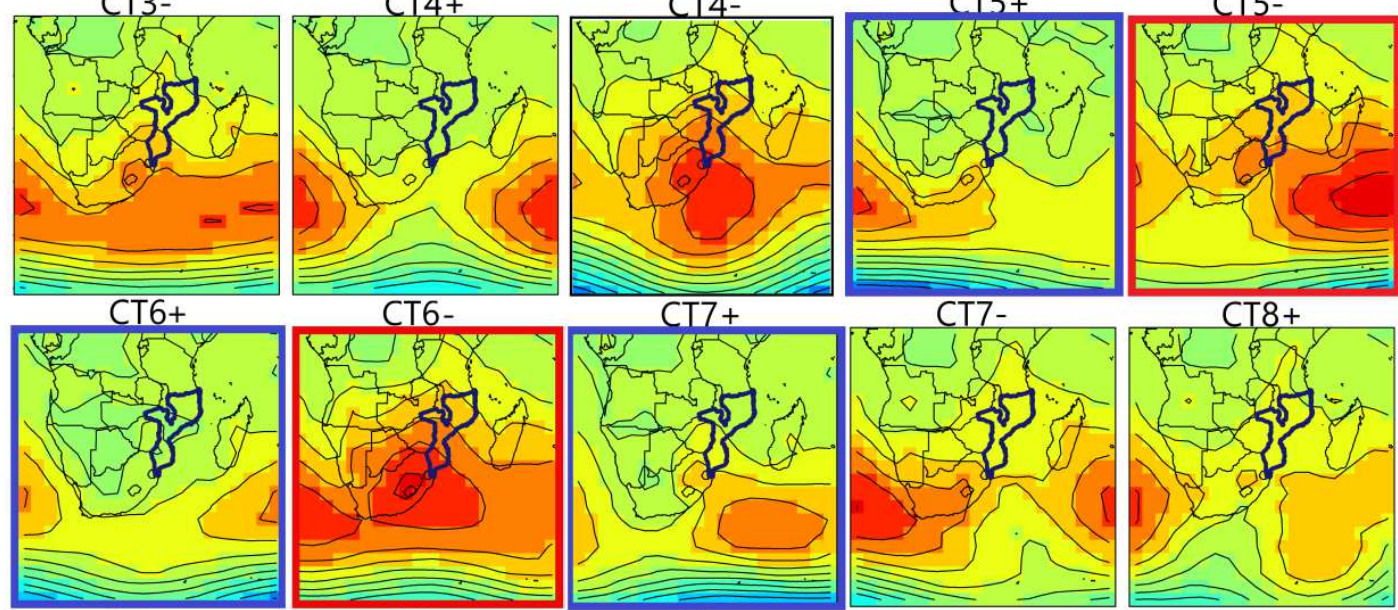

1020
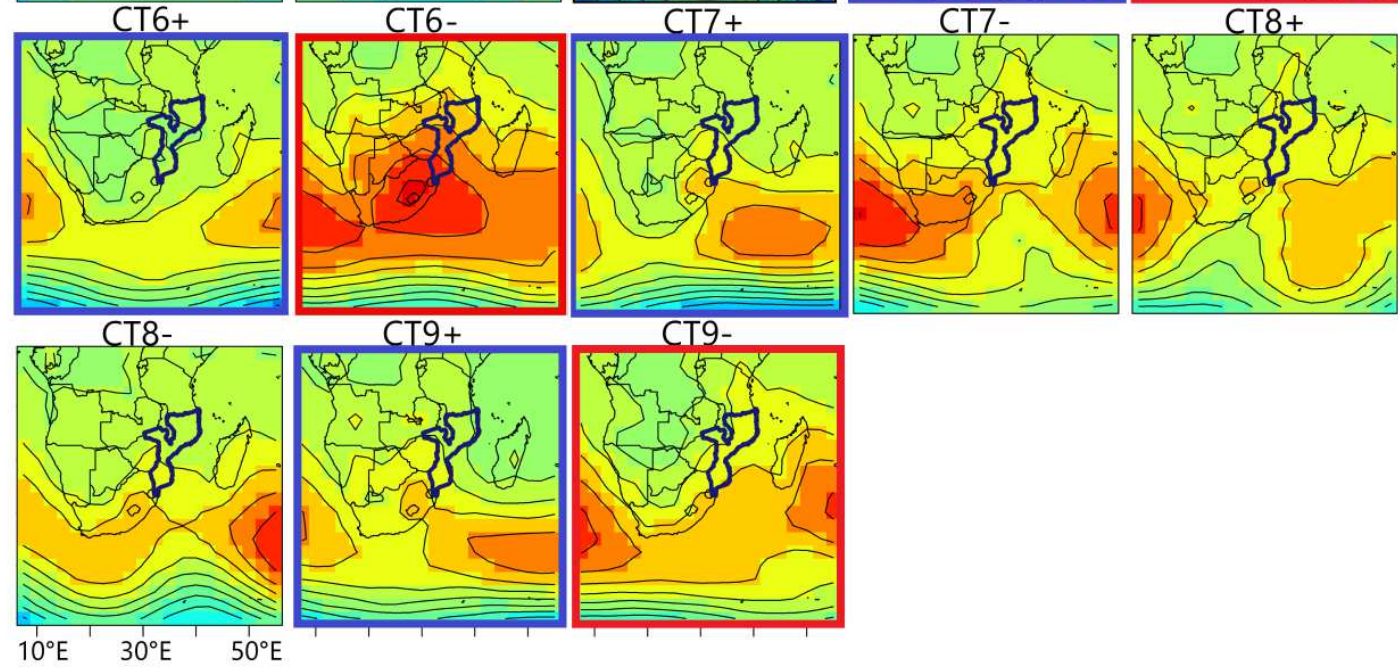

$-1010$

005

b) 


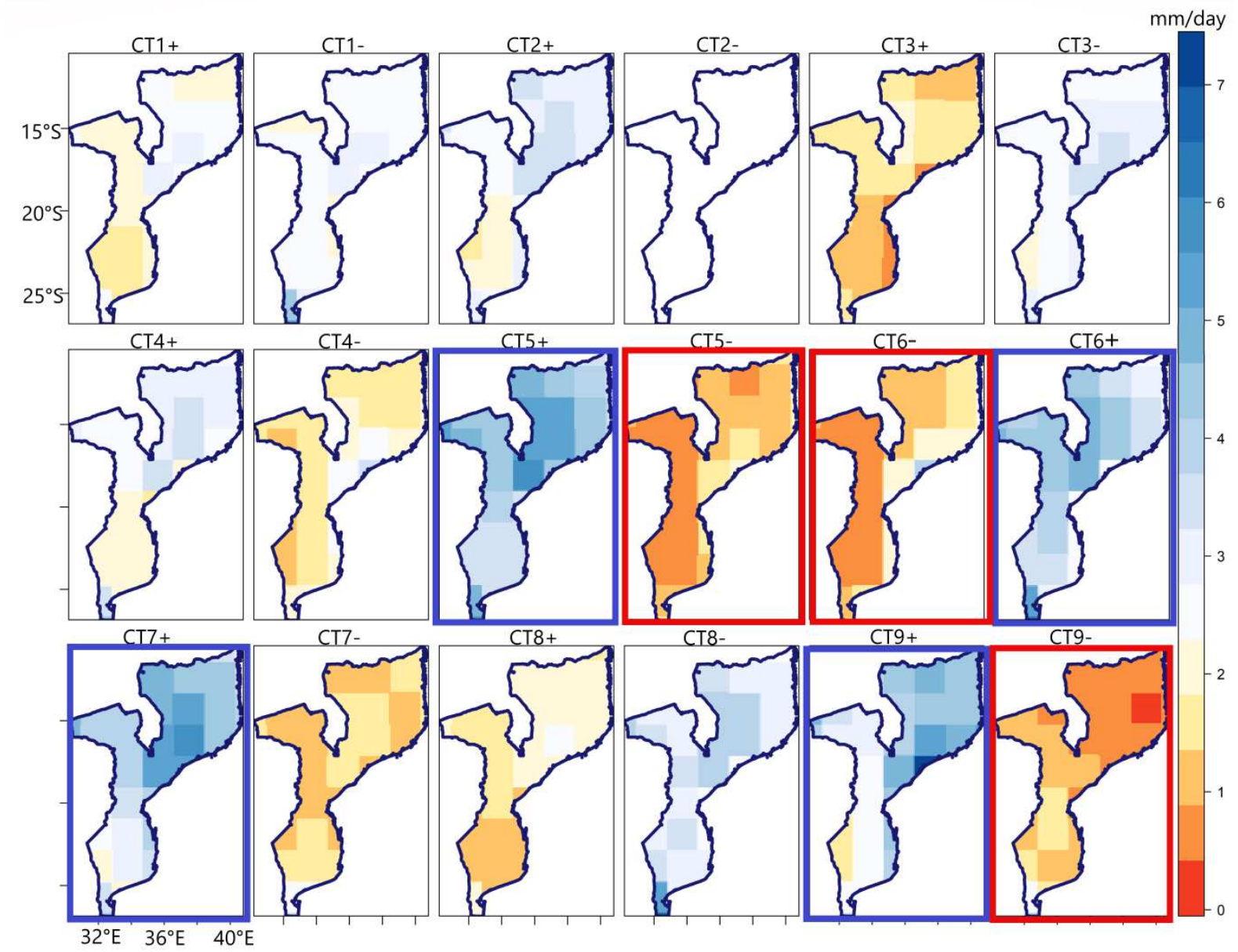

630 Fig. 2: Circulation types (a) and rainfall composites of the circulation types (b).

631 Circulations are the mean SLP field for the days clustered under a given class. Each retained

632 component yields two CTs - positive clusters and negative clusters above the \pm 0.2 threshold.

633

634

635

636

637

638 a) 


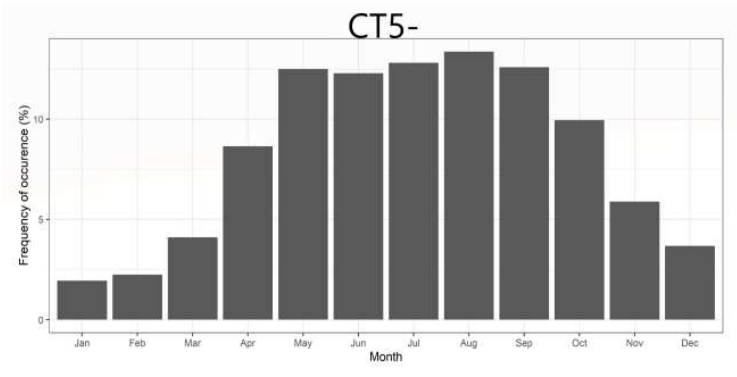

CT6-

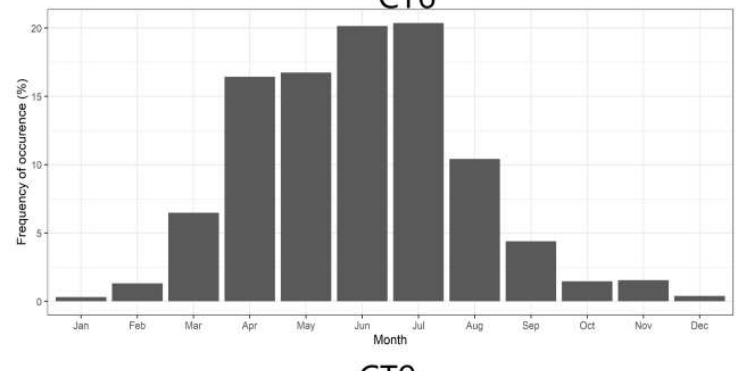

СТ9-

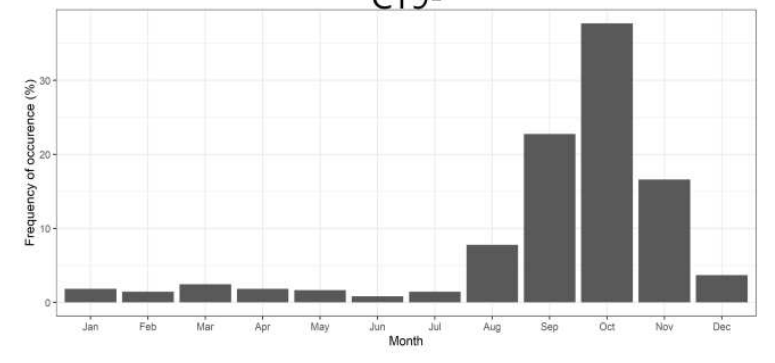

639

640

b)

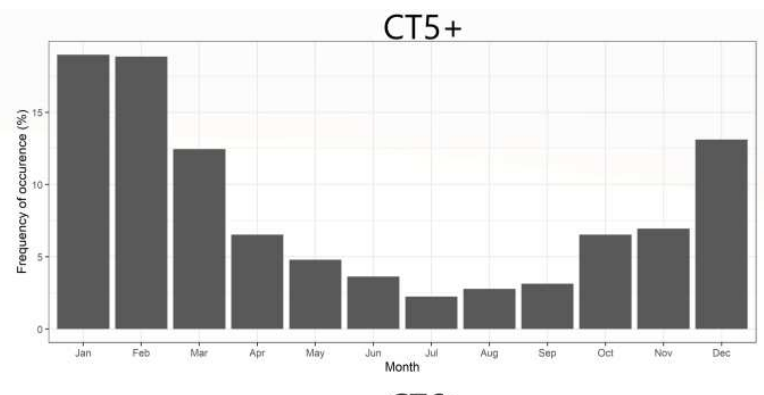

CT6+
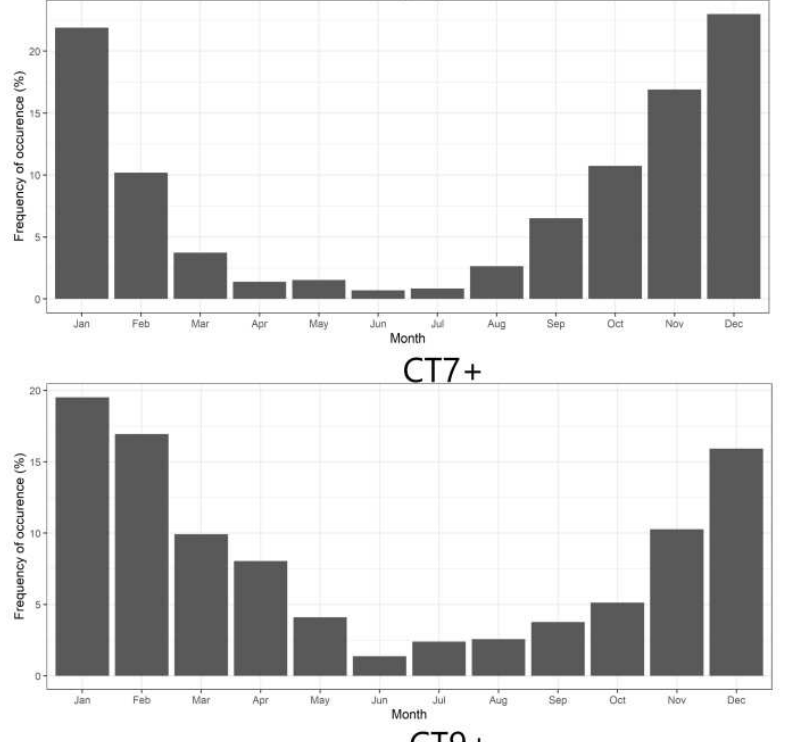

СT9+

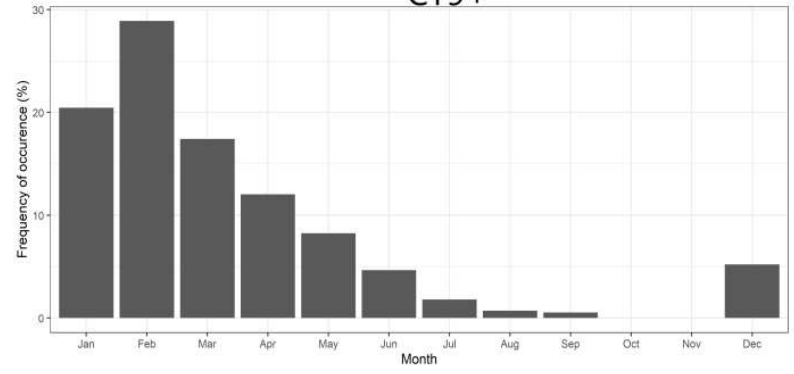


CT5-

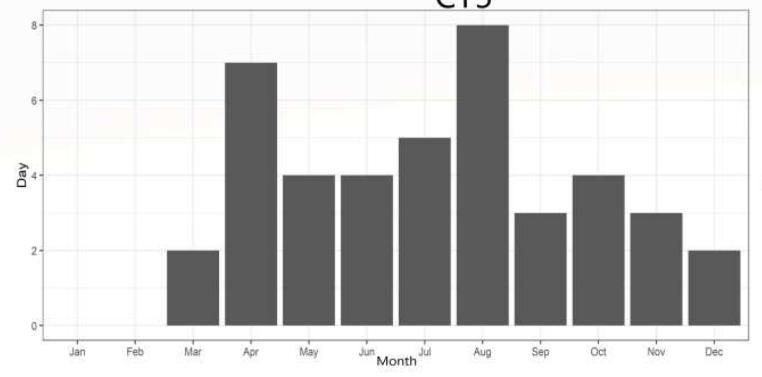

CT6-
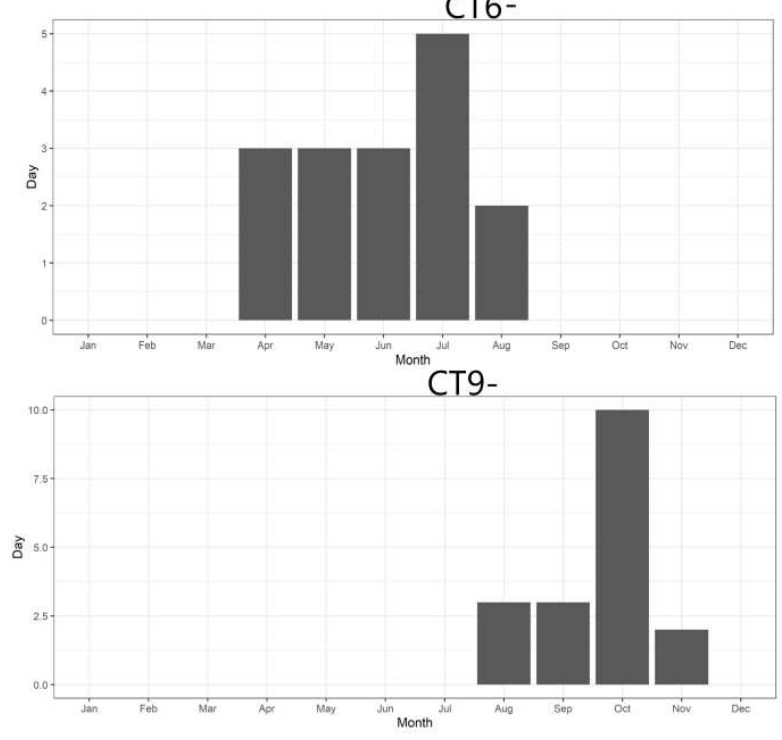

641

642
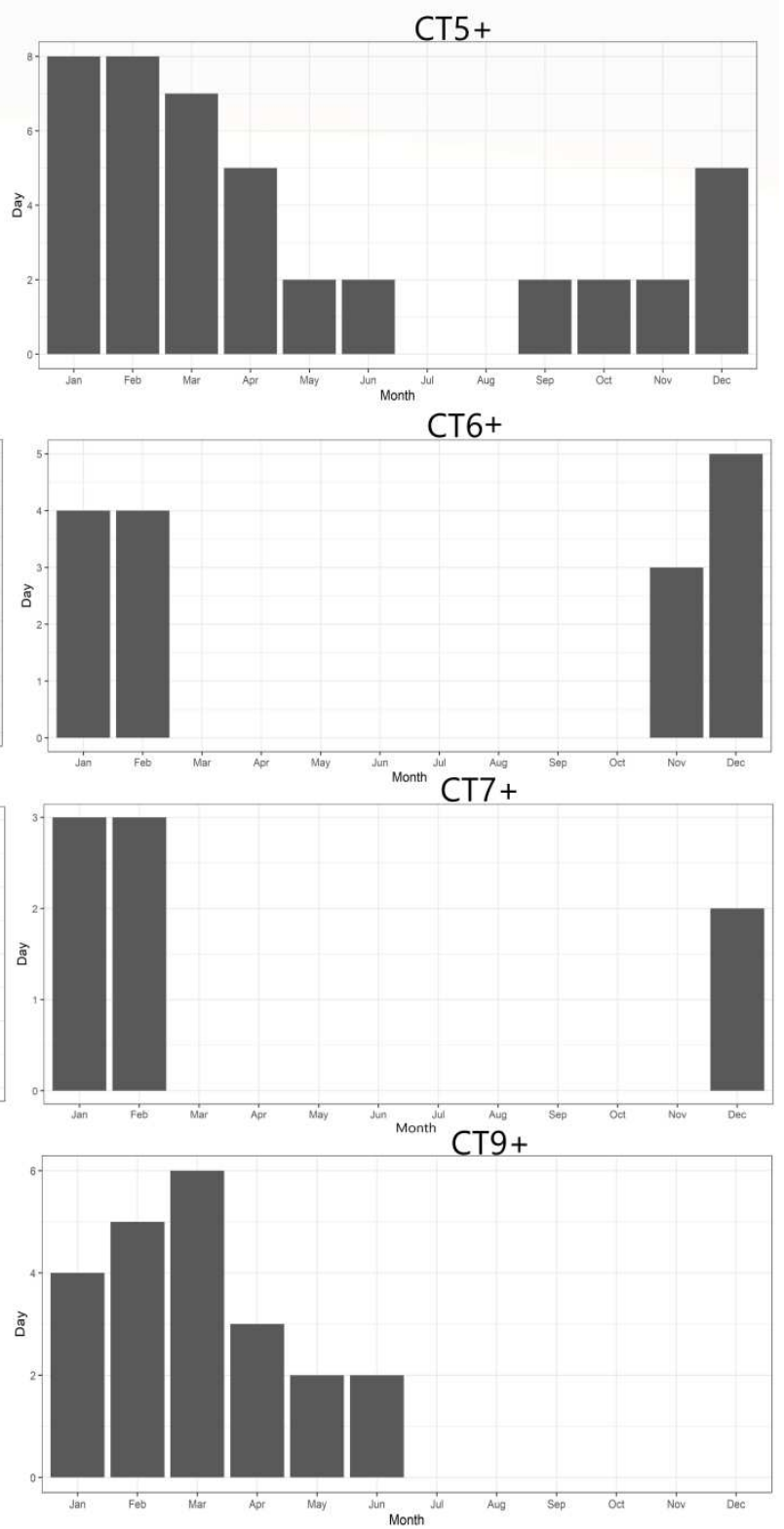

Fig. 3: Frequency of occurrence (a) and mean days of persistence (b) for the CTs 643 associated with wet and dry conditions in Mozambique. 

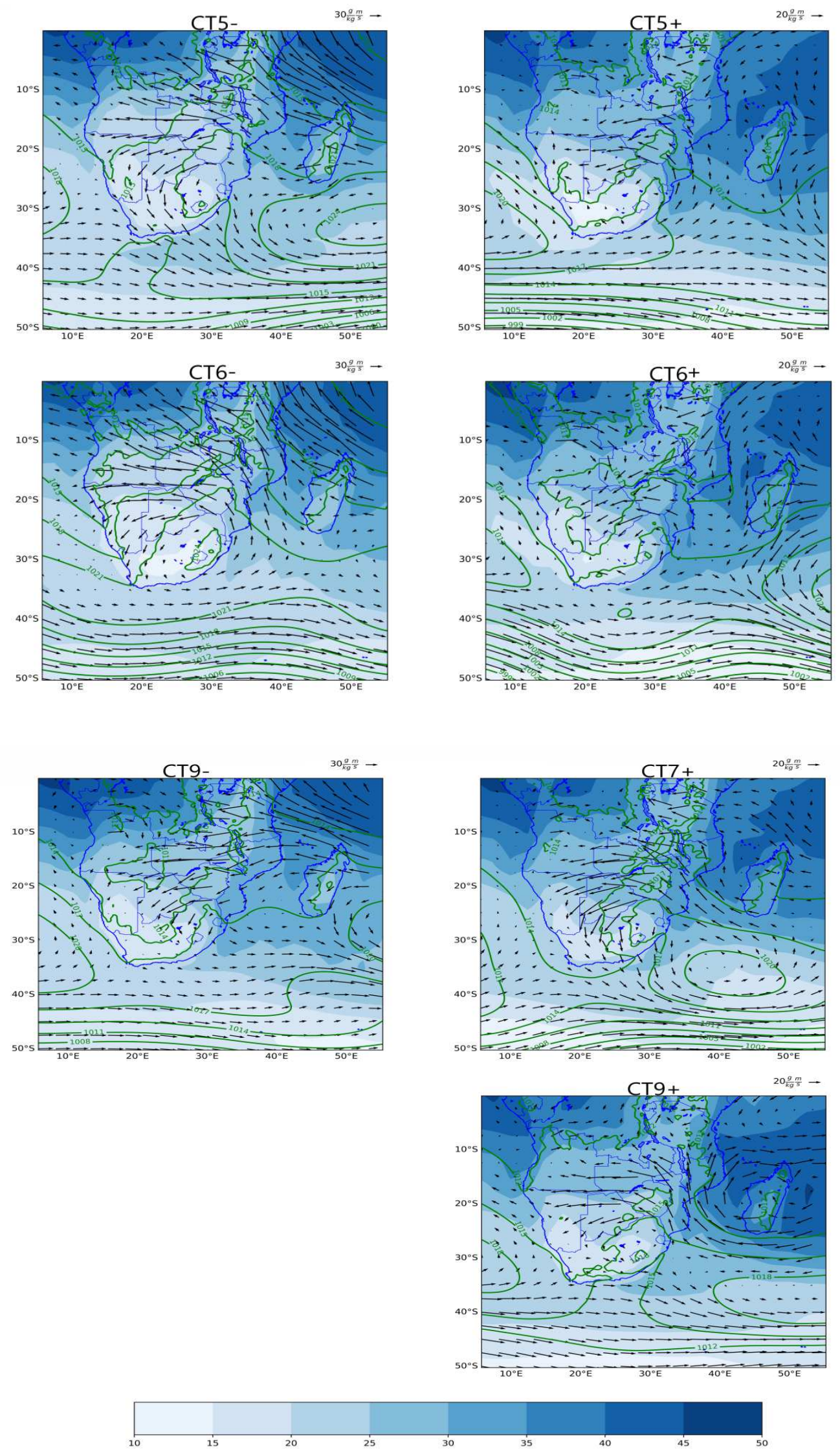
646 Fig. 4: Composites of SLP, precipitable water, and moisture flux at $850 \mathrm{hPa}$ for the wet 647 and dry CTs. Color is precipitable water with the unit in $\mathrm{mm}$. Contour is SLP in hPa and 648 contour interval is $3 \mathrm{hPa}$. Vector is moisture flux and the scale of the vector is written on the 649 maps 

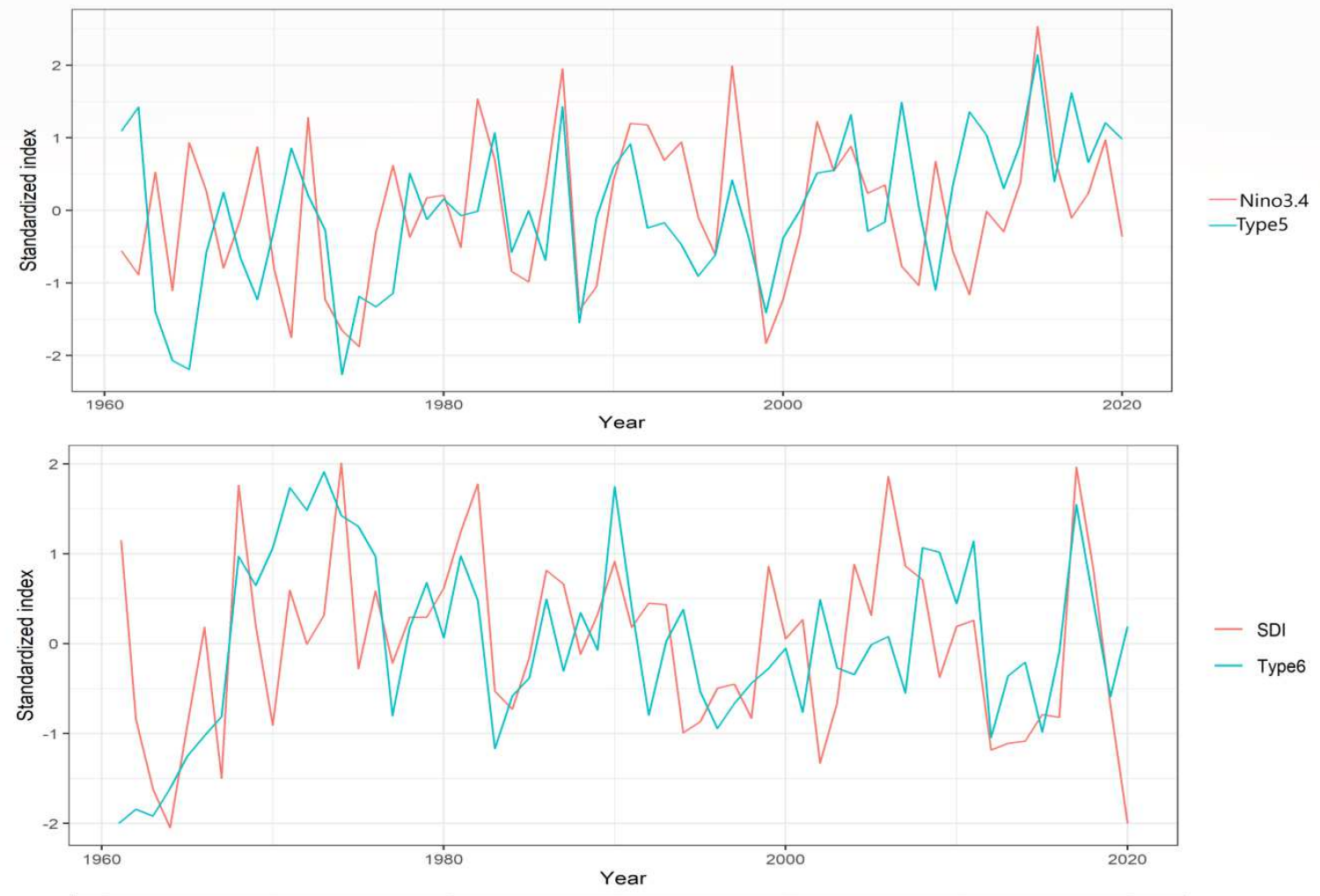

- SDI
- Type6
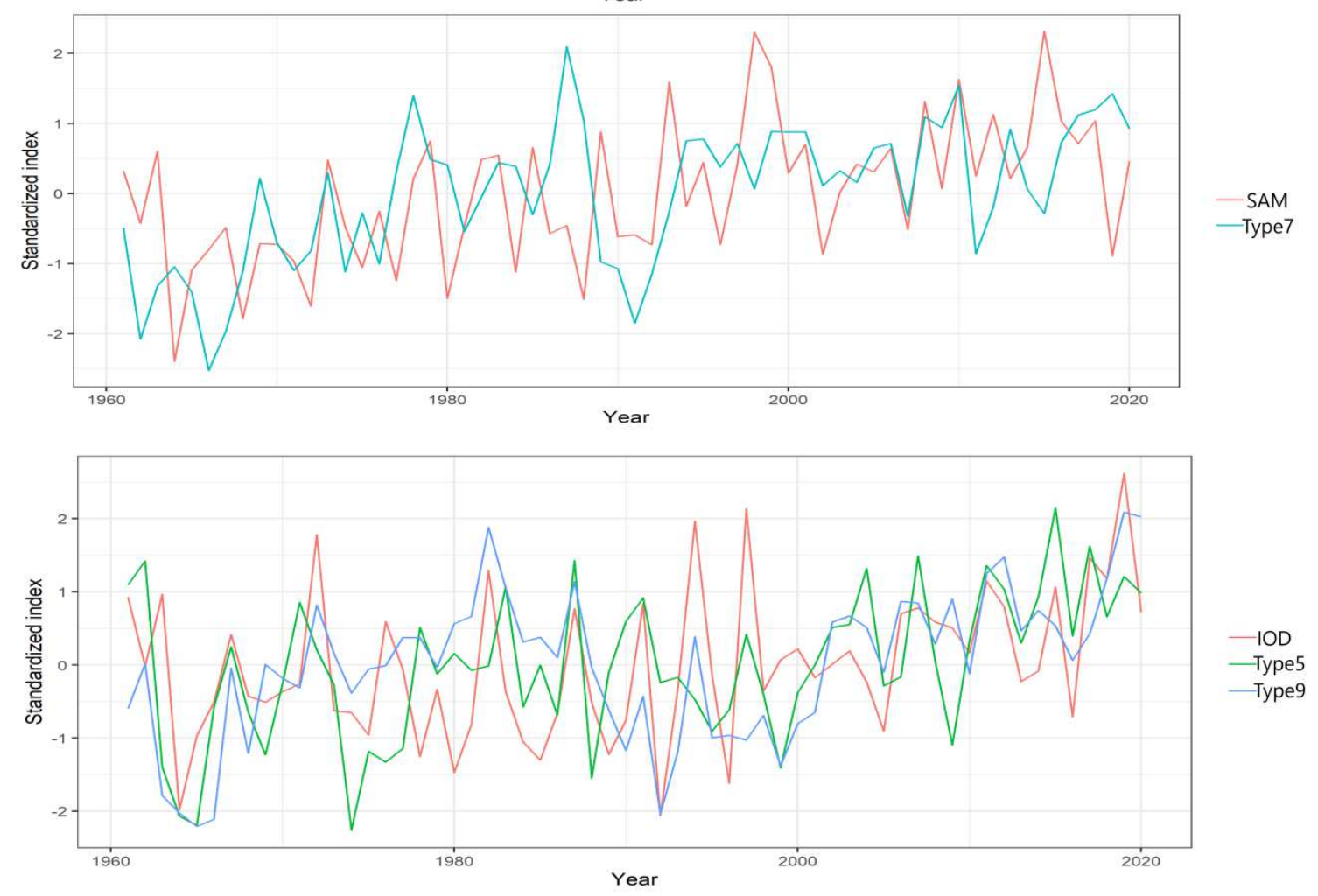

651 Fig. 5: Time series of the input patterns associated with wet and dry conditions in 652 Mozambique and the climatic modes in the south Indian Ocean that they are statistically 653 related to. 
CT5-
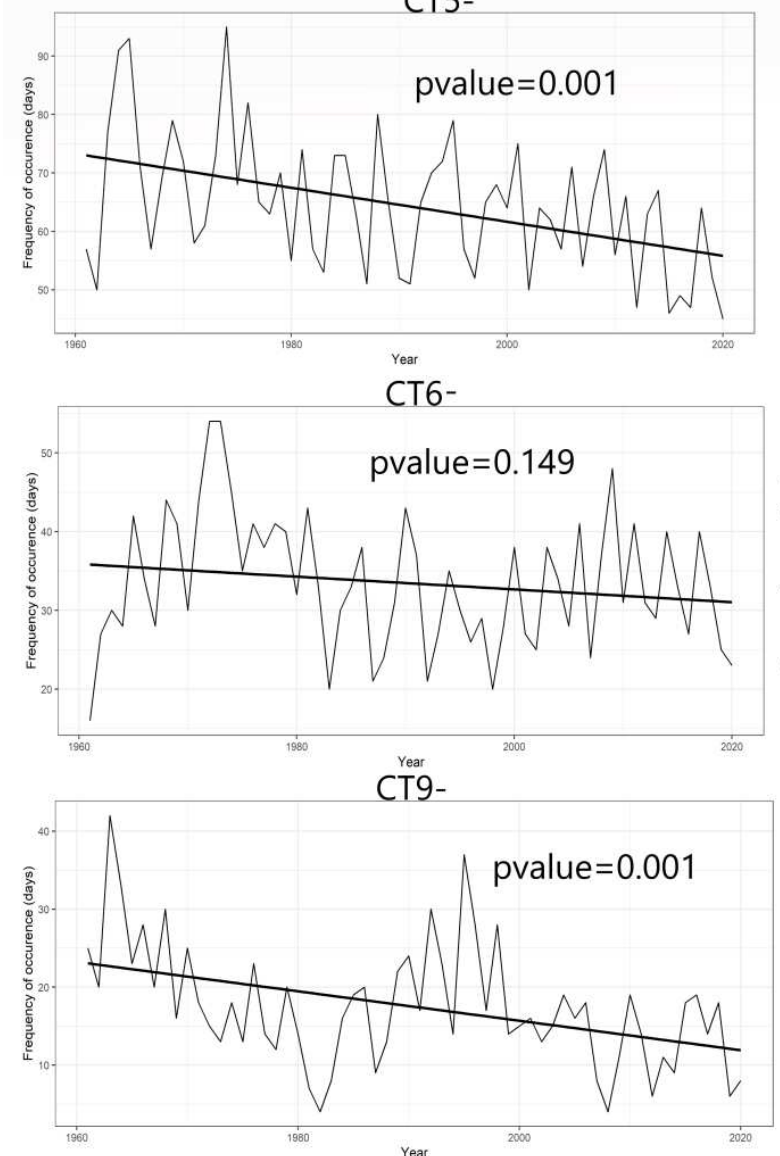

656

657

658

659

660

661
CT5+
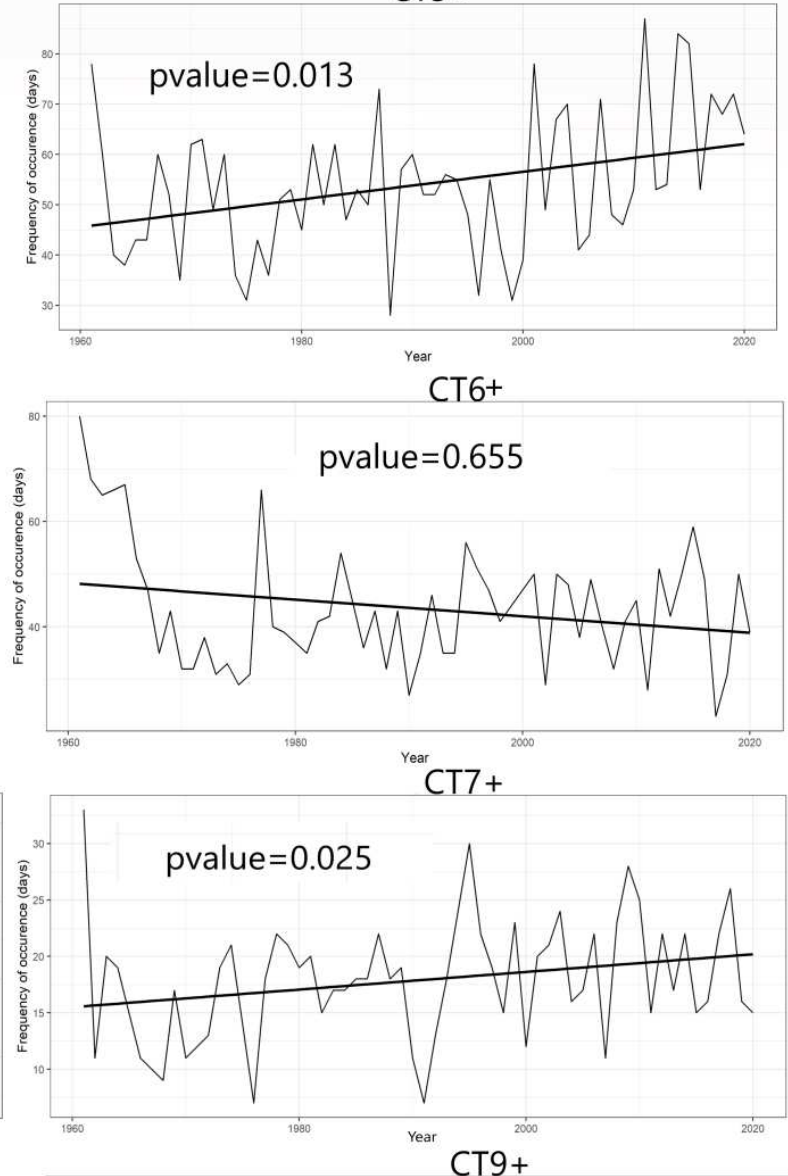

CT9+

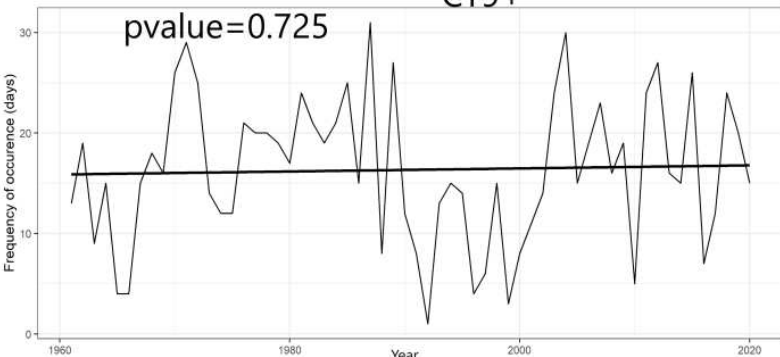

Fig. 6: Trend analysis of the CTs associated with wet and dry conditions in Mozambique for the 1961-2020 period. The black line is the linear regression line and the pvalue is from the Mann-Kendall test of linear trends at a 95\% confidence level. 
662

663

664

665

666

667

668

669

670

671 

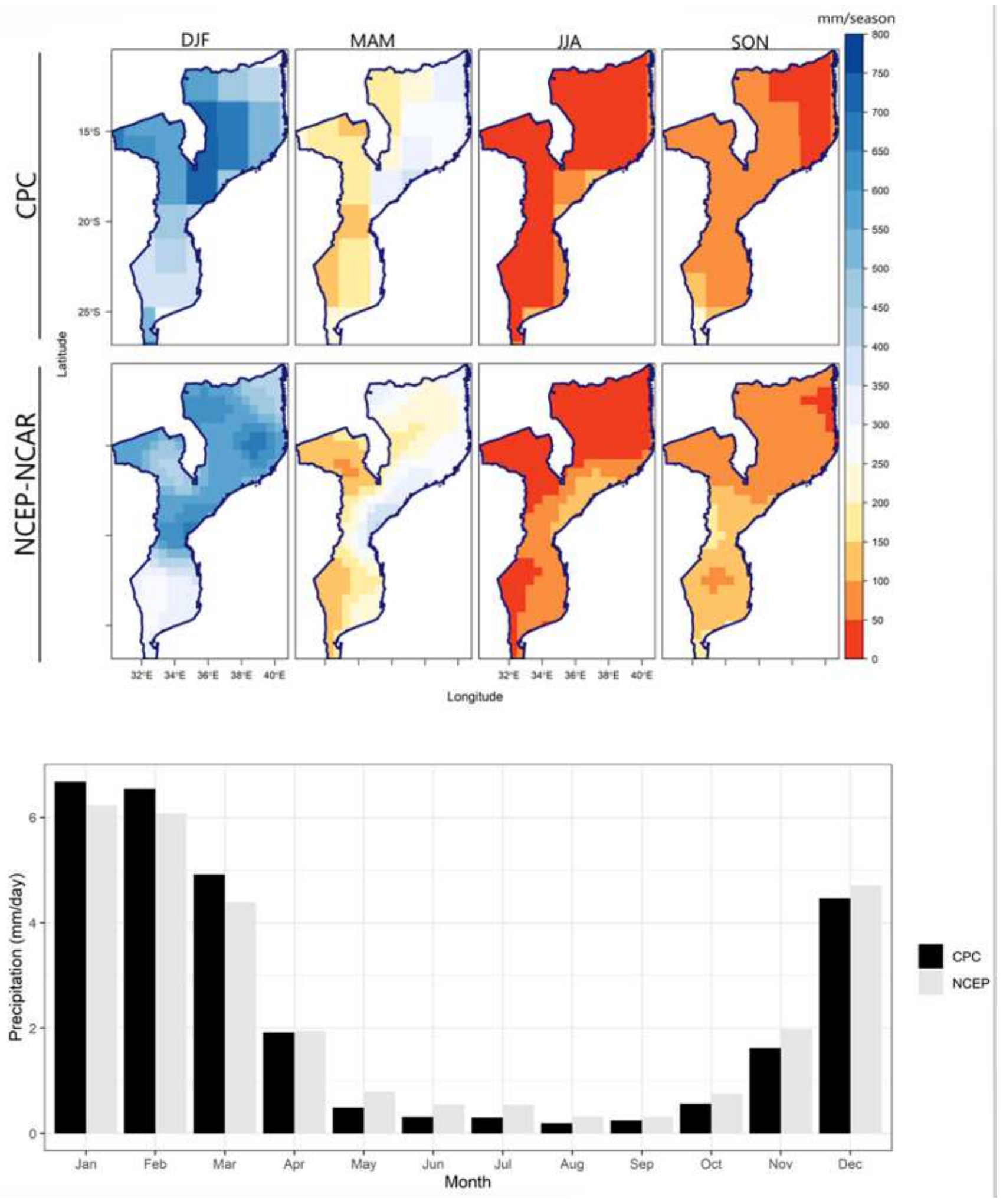

Figure 1

Seasonal rainfall climatology in Mozambique from the CPC and NCEP-NCAR precipitation data sets (top panel) and the monthly cycle of precipitation in Mozambique from the data sets. 
a)

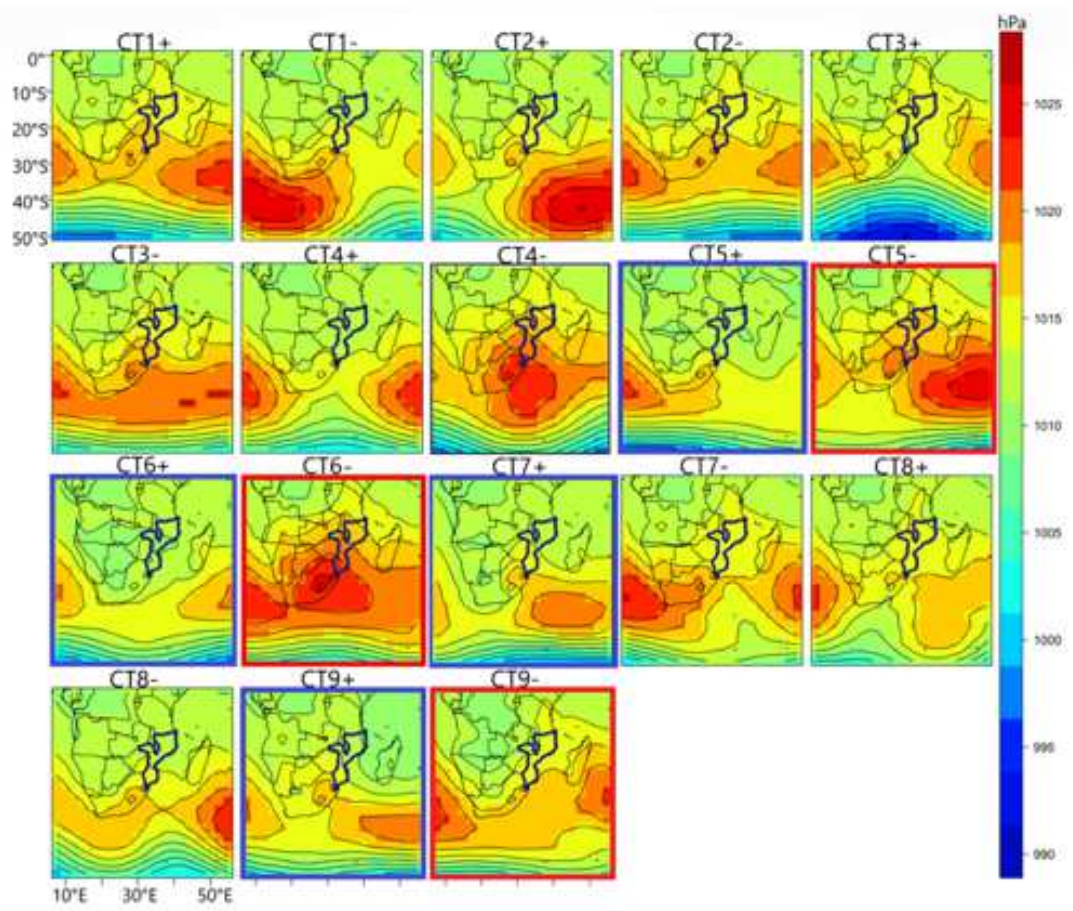

b)

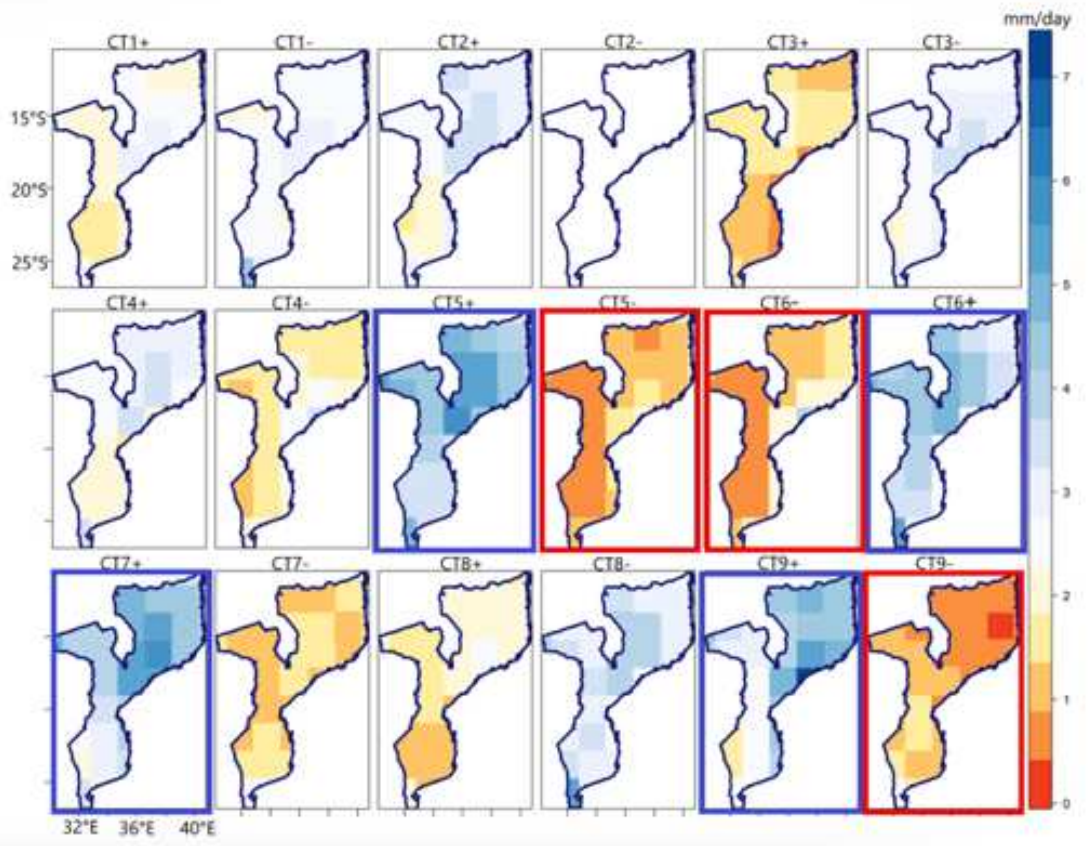

Figure 2

Circulation types (a) and rainfall composites of the circulation types (b). Circulations are the mean SLP field for the days clustered under a given class. Each retained component yields two CTs - positive clusters and negative clusters above the \pm 0.2 threshold. 
a)
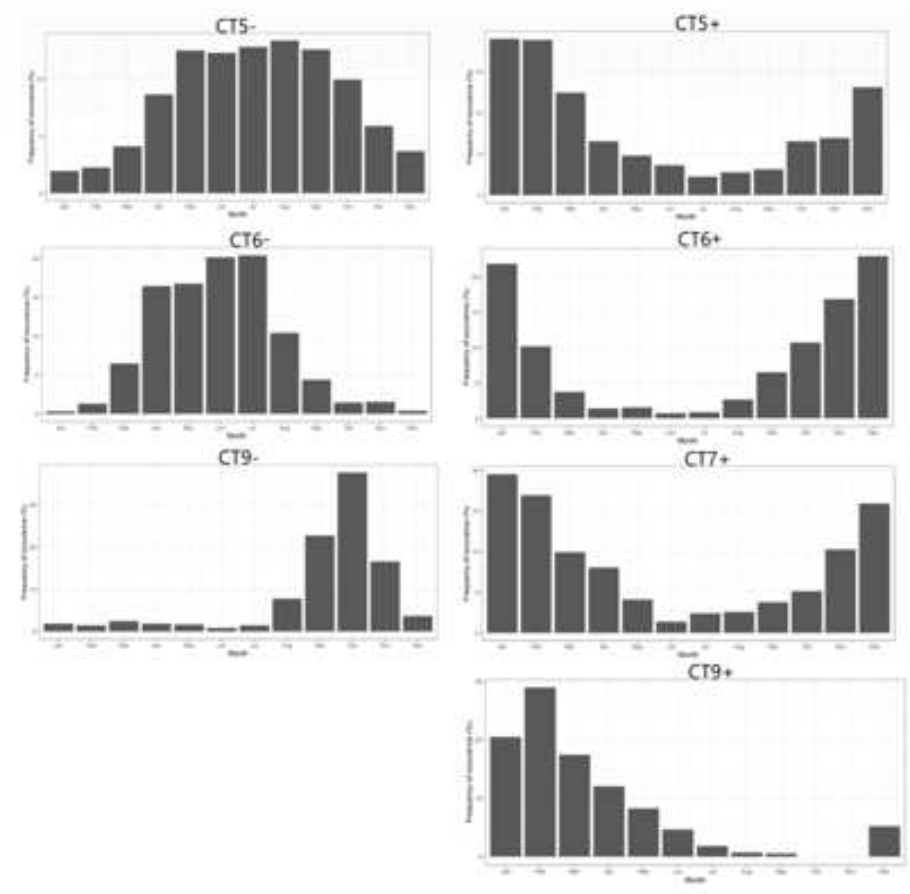

b)

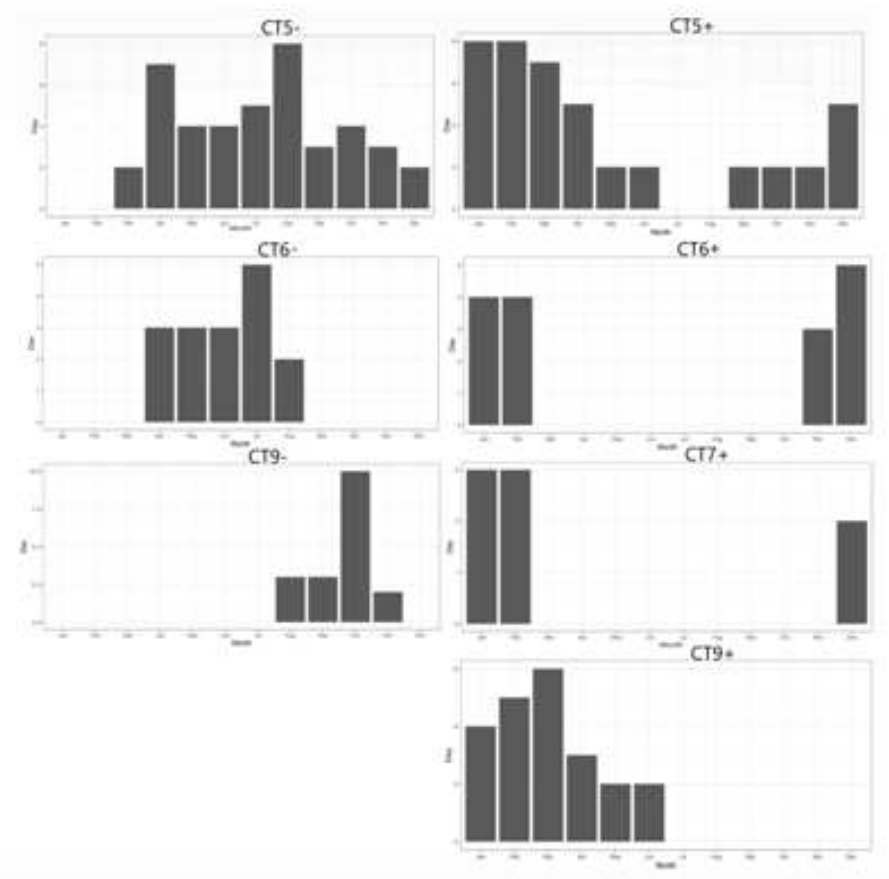

Figure 3

Frequency of occurrence (a) and mean days of persistence (b) for the CTs associated with wet and dry conditions in Mozambique. 

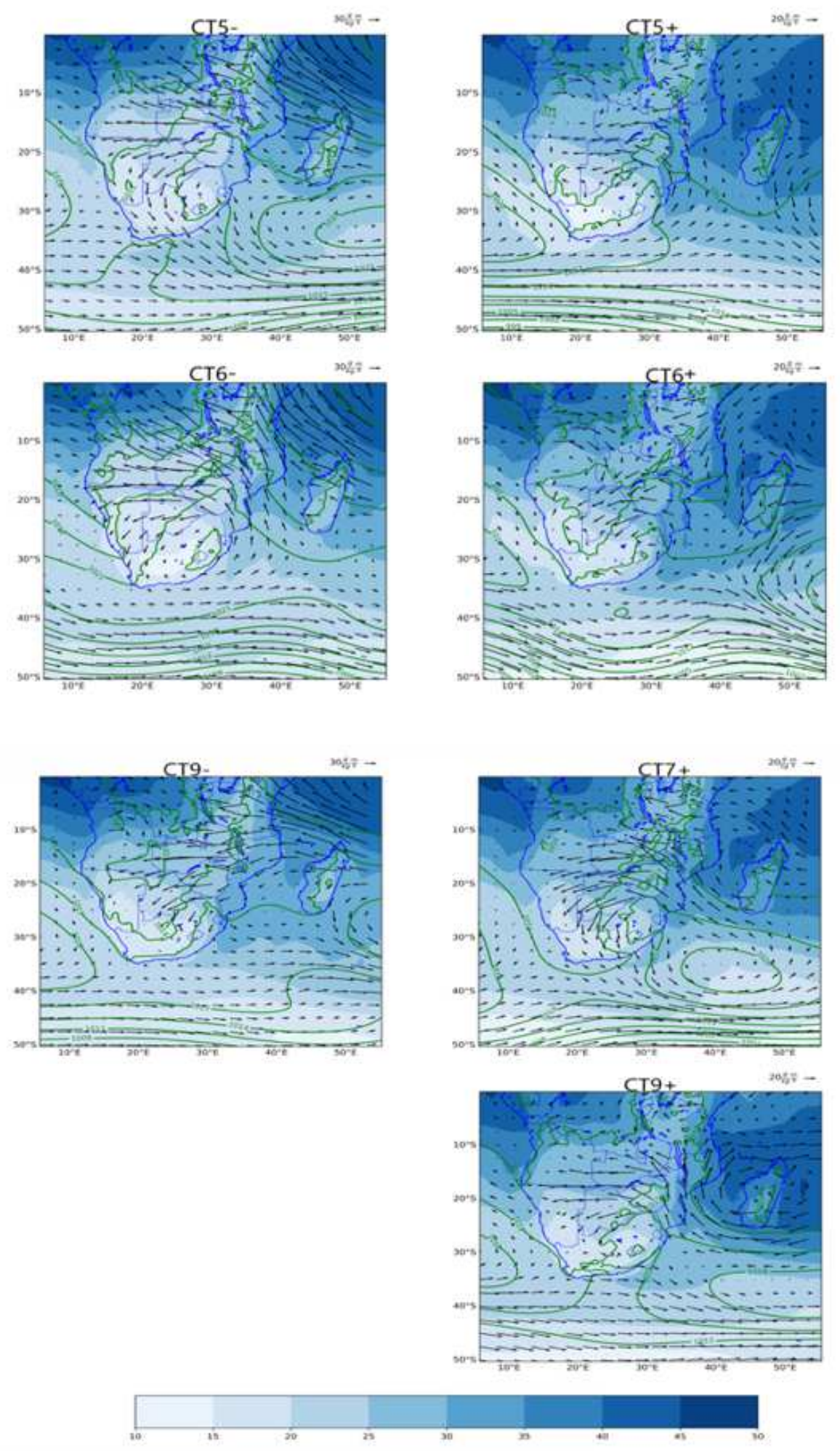

\section{Figure 4}

Composites of SLP, precipitable water, and moisture flux at $850 \mathrm{hPa}$ for the wet and dry CTs. Color is precipitable water with the unit in $\mathrm{mm}$. Contour is SLP in hPa and contour interval is $3 \mathrm{hPa}$. Vector is moisture flux and the scale of the vector is written on the maps 

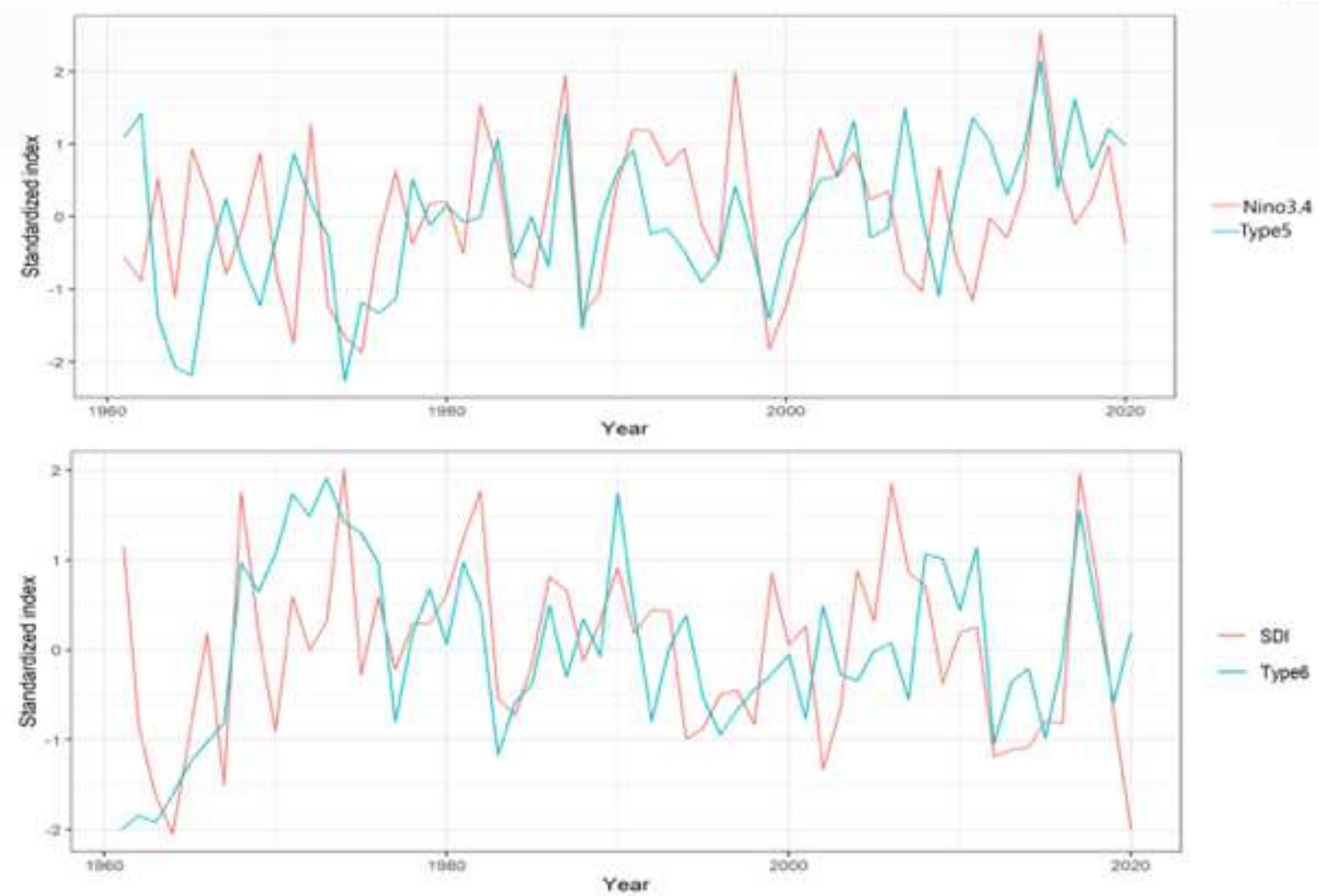

- sor

- Types

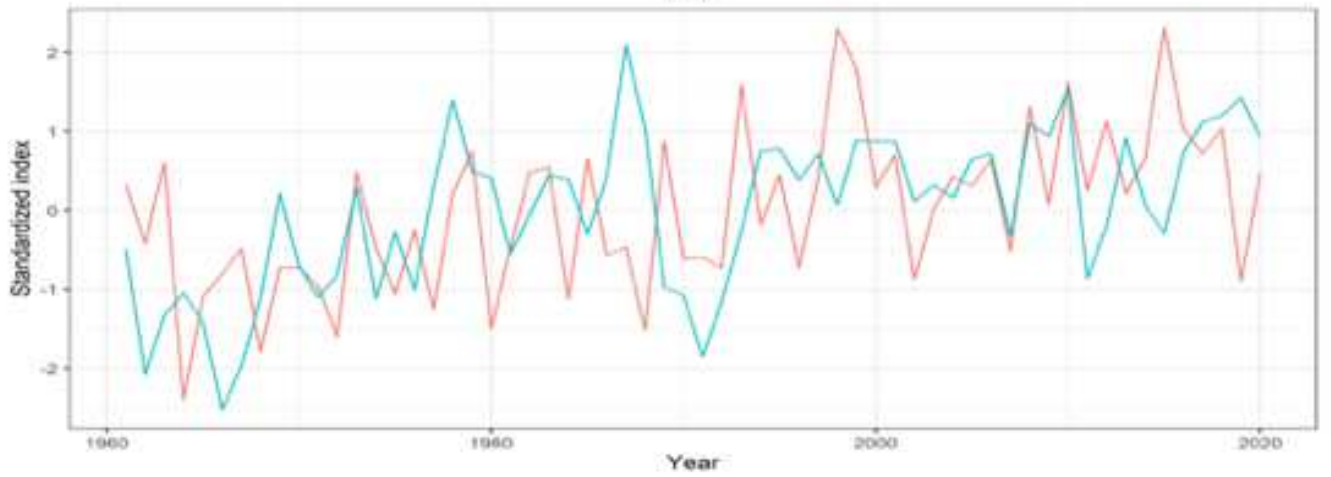

-SAM
- Type?
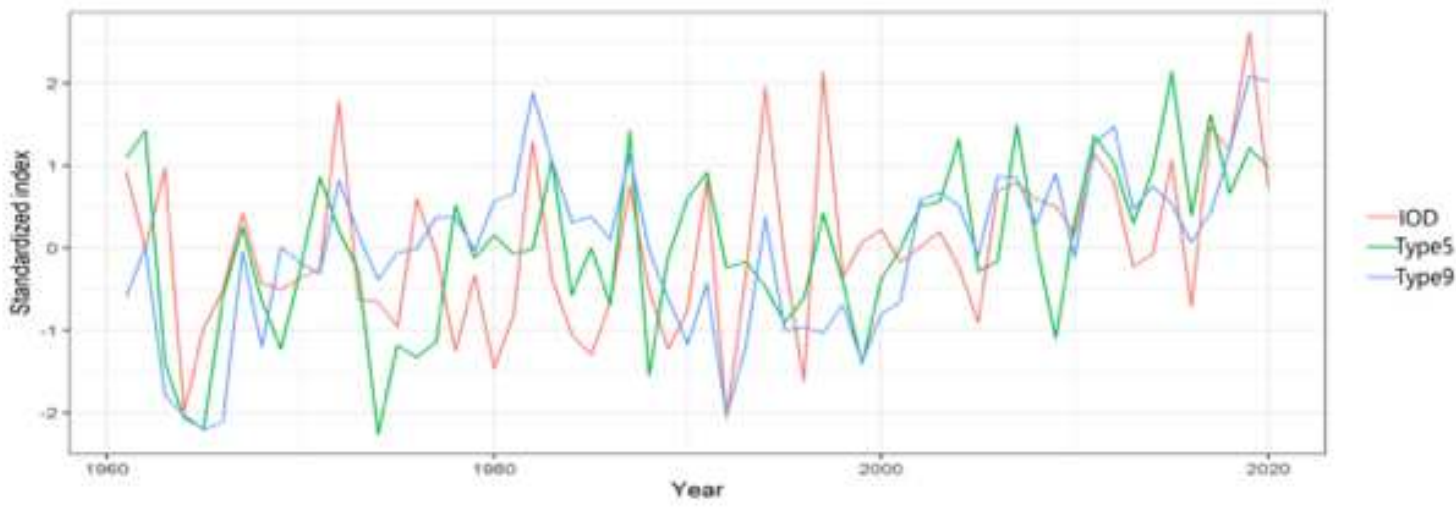

Figure 5

Time series of the input patterns associated with wet and dry conditions in Mozambique and the climatic modes in the south Indian Ocean that they are statistically related to. 

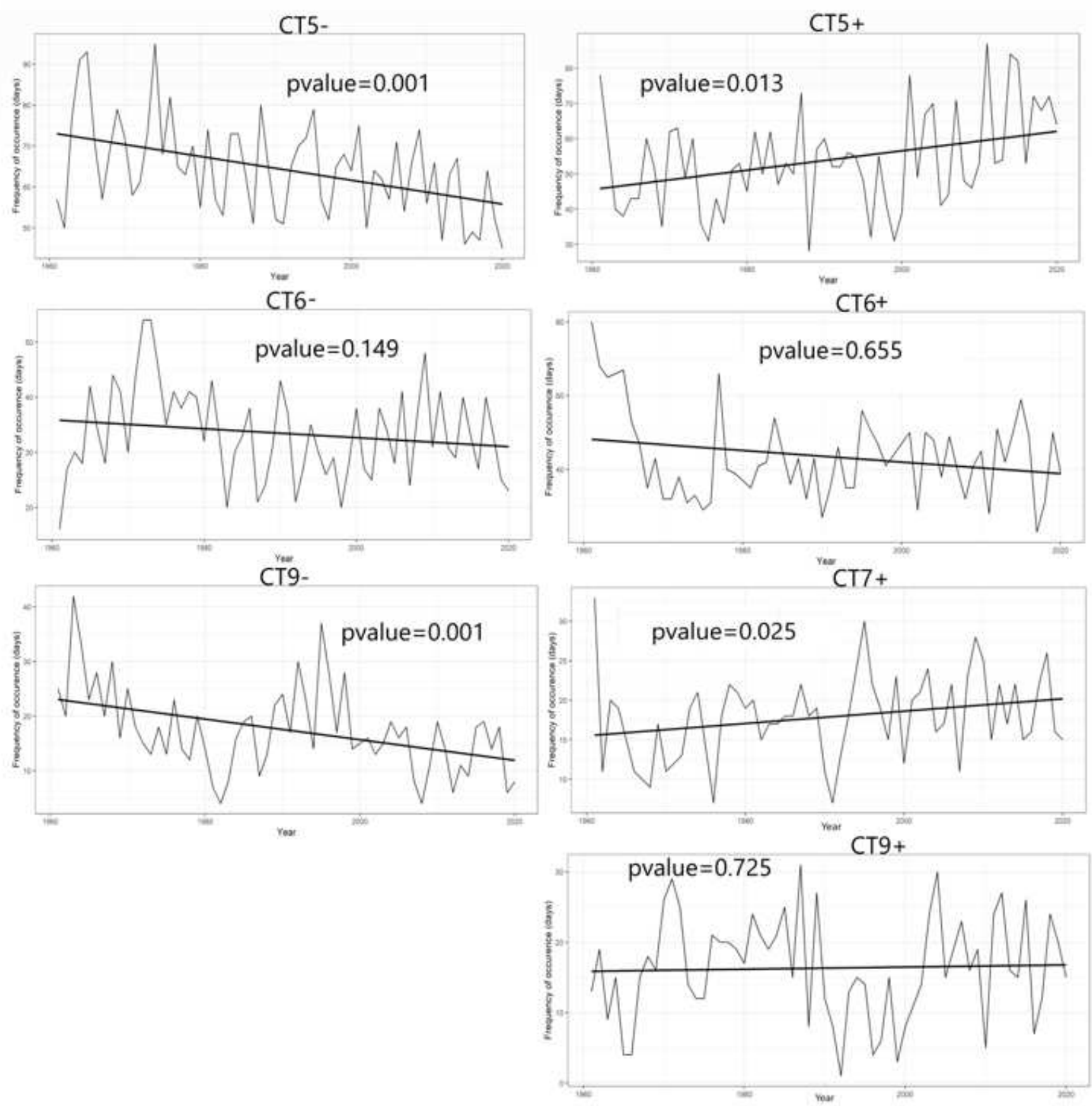

Figure 6

Trend analysis of the CTs associated with wet and dry conditions in Mozambique for the 1961-2020 period. The black line is the linear regression line and the pvalue is from the Mann-Kendall test of linear trends at a $95 \%$ confidence level. 